\title{
Combination of graphene oxide-silver nanoparticle nanocomposites and cisplatin enhances apoptosis and autophagy in human cervical cancer cells
}

This article was published in the following Dove Press journal:

International Journal of Nanomedicine

5 September 2017

Number of times this article has been viewed

\author{
Yu-Guo Yuan ${ }^{1,2}$ \\ Sangiliyandi Gurunathan ${ }^{3}$ \\ 'College of Veterinary Medicine/ \\ Animal Science and Technology/Jiangsu \\ Co-Innovation Center for Prevention \\ and Control of Important Animal \\ Infectious Diseases and Zoonosis, \\ Yangzhou University, Yangzhou, Jiangsu, \\ China; ${ }^{2}$ Jiangsu Key Laboratory of \\ Integrated Traditional Chinese and \\ Western Medicine for Prevention \\ and Treatment of Senile Diseases, \\ Yangzhou University, Yangzhou, \\ China; ${ }^{3}$ Department of Stem Cell and \\ Regenerative Biotechnology, Konkuk \\ University, Seoul, Republic of Korea
}

Background: Cisplatin (Cis) is a widely used chemotherapeutic drug for treating a variety of cancers, due to its ability to induce cell death in cancer cells significantly. Recently, graphene and its modified nanocomposites have gained much interest in cancer therapy, due to their unique physicochemical properties. The objective of this study was to investigate the combination effect of Cis and a reduced graphene oxide-silver nanoparticle nanocomposite (rGO-AgNPs) in human cervical cancer (HeLa) cells.

Materials and methods: We synthesized AgNPs, rGO, and rGO-AgNP nanocomposites using C-phycocyanin. The synthesized nanomaterials were characterized using various analytical techniques. The anticancer properties of the Cis, rGO-AgNPs, and combination of Cis and rGO-AgNPs were evaluated using a series of cellular assays, such as cell viability, cell proliferation, LDH leakage, reactive oxygen species generation, and cellular levels of oxidative and antioxidative stress markers such as malondialdehyde, glutathione, SOD, and CAT. The expression of proapoptotic, antiapoptotic, and autophagy genes were measured using real-time reverse-transcription polymerase chain reaction.

Results: The synthesized AgNPs were well dispersed, homogeneous, and spherical, with an average size of $10 \mathrm{~nm}$ and uniformly distributed on graphene sheets. Cis, GO, rGO, AgNPs, and rGO-AgNPs inhibited cell viability in a dose-dependent manner. The combination of Cis and rGO-AgNPs showed significant effects on cell proliferation, cytotoxicity, and apoptosis. The combination of $\mathrm{Cis}$ and $\mathrm{rGO}-\mathrm{AgNPs}$ had more pronounced effects on the expression of apoptotic and autophagy genes, and also significantly induced the accumulation of autophagosomes and autophagolysosomes, which was associated with the generation of reactive oxygen species.

Conclusion: Our findings substantiated rGO-AgNPs strongly potentiating Cis-induced cytotoxicity, apoptosis, and autophagy in HeLa cells, and hence rGO-AgNPs could be potentially applied to cervical cancer treatment as a powerful synergistic agent with Cis or any other chemotherapeutic agents.

Keywords: cisplatin, graphene oxide-silver nanoparticles nanocomposites, oxidative stress, cell viability, apoptosis, autophagy

\section{Introduction}

Cervical cancer is one of the most aggressive gynecological cancers and is still a major cause of morbidity and mortality in women worldwide. ${ }^{1,2}$ It ranks third among frequently diagnosed cancers and fourth in leading causes of cancer death among females worldwide. ${ }^{3}$ About 500,000 new cases are diagnosed annually, which accounts for around $12 \%$ of all cancers diagnosed in women worldwide. ${ }^{4}$ The occurrence and progression of cervical cancer are believed to be related to abnormal 
genetic and epigenetic regulation, including phosphorylation and acetylation of histone H3, global DNA hypomethylation, and hypermethylation of tumor-suppressor genes. ${ }^{5,6}$ The American Cancer Society reported that 12,990 new cases of invasive cervical cancer would be diagnosed in 2016 and 4,120 women die from the disease. ${ }^{7}$ Unlike the majority of other gynecological malignancies, cervical cancer is clinically staged prior to surgery. Early stages are often treated surgically, but cervical cancer with distant metastases or recurrence remains uniformly fatal. ${ }^{8}$

There are several approaches for cancer treatment, including surgery, radiation therapy, hormonal therapy, chemotherapy (either alone or in combination), and targeted therapy. Surgery is the primary treatment for early stage cervical cancer. Radiotherapy or chemoradiotherapy is often used for patients with advanced-stage cervical cancer. ${ }^{9,10}$ Chemotherapy seems to be a powerful therapeutic approach for the treatment and management of cancer, which is also supplementing other strategies such as surgery and radiation therapy. ${ }^{11}$ Among the various chemical reagents used in chemotherapy, such as cisplatin (Cis), carboplatin, paclitaxel, topotecan, gemcitabine, the platinum-based chemical reagents are most commonly used. ${ }^{9}$ The anticancer efficacies of current therapies are limited, due to the high degree of cancer clonal heterogeneity and drug resistance. In addition, using a single therapeutic agent is not effective in eradicating cancer cells, and hence the use of combinatorial therapy, which could inhibit multiple targets or redundant pathways simultaneously, is essential and inevitable. ${ }^{12}$

Recently, nanotechnology has offered several potential applications and the opportunity to improve drug solubility and stability, extensive drug half-lives in plasma, minimize off target effects, concentrate drugs at a target site, and increase cancer-cell cytotoxicity. ${ }^{13,14}$ Cancer treatments based on single-agent treatment are often associated with limited therapeutic efficacy, drug resistance, and unnecessary side effects. Combination therapy using two or chemotherapeutic agents is an alternative promising strategy for effective cancer treatment, due to its synergistic effect. ${ }^{15}$ To overcome nonselective distribution of the drug between normal and tumor tissue, nanoparticles (NPs) are being used as drug-delivery agents or single cytotoxic agents for cancer cells, due to their unique characteristics, such as the enhanced permeability and retention effect. ${ }^{16}$ Several inorganic NPs have been used with Cis to enhance the effect, eg, ferromagnetic NPs show a synergistic effect with $\mathrm{Cis}$ in hyperthermia on the microvasculature, stroma, and/or tumor cells, leading to enhanced accumulation, uptake, and effects of multiple cytotoxic agents. ${ }^{17}$
The combination of gold NPs and Cis has shown enhanced cellular uptake and cytotoxicity in mouse models. ${ }^{18}$ The combination of silver NPs and salinomycin has shown enhanced apoptosis and autophagy in human ovarian cancer cells. ${ }^{13}$ Furthermore, trichostatin A potentiates the apoptotic potential of palladium NPs in human cervical cancer cells. ${ }^{19}$

Graphene is a single-layer planar sheet of $\mathrm{sp}^{2}$-bonded carbon atoms that are packed in a two-dimensional honeycomb lattice. ${ }^{20}$ Graphene is obtained by reduction of graphene oxide (GO). Unfortunately, as a material GO does not have some of the attractive properties of graphene; therefore, it is necessary to prepare a reduced form of GO (rGO) for the improvement of various properties. Several methods have been established to reduce GO using physical, chemical, mechanical, and biological means. Although chemical methods appear to be simple and easy for synthesis, the use of chemical reducing agents is harmful to human beings. ${ }^{21-23}$ Therefore, finding alternative processes becomes essential, apparently leading to biological methods that are well appreciated for their viable and environment-friendly approach, with the added advantage of providing solubility to $\mathrm{rGO}$, due to its biomolecular properties. ${ }^{21}$

Graphene and graphene-related materials have been studied extensively for cellular toxicity in various cancer cells, including human alveolar basal epithelial (A549) cells, human breast cancer cells, ${ }^{22}$ and human ovarian cancer cells, ${ }^{23}$ due their unique properties. Similarly, the anticancer properties of silver NPs have been investigated in various cancer cell lines, including human breast cancer cells ${ }^{24}$ and human lung cancer cells. ${ }^{25}$ The synthesis of graphene composites with various metal NPs has evoked much interest, due to their unique properties and enhanced antibacterial activity. ${ }^{26}$ In addition, graphene offers a suitable platform for the development of nanocomposites, allowing the combination of nanomaterials with different properties to give novel materials improved or new functionality. Particularly, GO is used for the attachment of AgNPs, ${ }^{21,27,28}$ due to its high surface area that serves as a support for growth and stabilization of NPs, which prevents them from aggregating. ${ }^{29}$ However, studies related to anticancer activity of GO-silver nanocomposites have been very limited. Recently, we showed superior anticancer activity of GO-silver nanocomposites over a single agent, such as either GO or AgNPs in human ovarian cancer cells. ${ }^{21} \mathrm{C}$ is is a well-known platinum-based chemotherapeutic drug that is used to treat a variety of cancers, including mesothelioma, ovarian, and breast and cervical cancers. A considerable number of studies have performed with a combination of various chemotherapeutic agents in 
different kinds of cancer cells. Considering the current literature, so far there has been no study reporting the biological activity of GO-AgNP nanocomposites in any type of cancer cells. Particularly, the combination of Cis with GO-AgNP nanocomposites for the treatment of cervical cancer has not been reported. It is clinically necessary to identify a possible alternative in new therapeutic molecules that may significantly enhance apoptosis in cancer cells. These kinds of studies remain subjects of particular interest in nanomedicine. Therefore, this study was designed with the following objectives. The first aim was to synthesize and characterize various types of nanomaterials, including AgNPs, rGO, and GO-AgNP nanocomposites using a biomolecule called C-phycocyanin from spirulina species. The second objective was to evaluate the combination effect of $\mathrm{Cis}$ and GO-AgNP nanocomposites on cervical cancer cells. The final objective was to evaluate the mechanistic effect of $\mathrm{Cis}$ and GO-AgNP nanocomposites on apoptosis and autophagy.

\section{Materials and methods Materials}

Penicillin-streptomycin, trypsin-ethylenediaminetetraacetic acid (EDTA), Dulbecco's Modified Eagle's Medium, Roswell Park Memorial Institute 1640 medium, and 1\% antibiotic-antimycotic were obtained from Thermo Fisher Scientific (Waltham, MA, USA). Cis, fetal bovine serum and an in vitro toxicology assay kit were purchased from SigmaAldrich (St Louis, MO, USA). C-phycocyanin, silver nitrate, graphite (Gt) powder, $\mathrm{NaOH}, \mathrm{KMnO}_{4}, \mathrm{NaNO}_{3}$, anhydrous ethanol, $98 \% \mathrm{H}_{2} \mathrm{SO}_{4}, 36 \% \mathrm{HCl}, 30 \% \mathrm{H}_{2} \mathrm{O}_{2}$ aqueous solution, and all other chemicals were purchased from Sigma-Aldrich unless otherwise stated.

\section{Synthesis of AgNPs and GO and reduction of $\mathrm{GO}$}

The synthesis of AgNPs was performed using C-phycocyanin according to a method described previously. ${ }^{30}$ AgNPs were prepared by adding $1 \mathrm{~mL}$ of $1 \mathrm{mg}$ C-phycocyanin to $10 \mathrm{~mL}$ $5 \mathrm{mM}$ aqueous $\mathrm{AgNO}_{3}$; the mixture was incubated for 6 hours at $40^{\circ} \mathrm{C}$ and $\mathrm{pH} 8$. Bioreduction of the silver ions was monitored spectrophotometrically at $420 \mathrm{~nm}$. Further characterization of the synthesized AgNPs was performed as described previously.

GO was synthesized as described previously, with suitable modifications. ${ }^{23,31}$ In a typical synthesis process, $2 \mathrm{~g}$ of natural Gt powder was added to $350 \mathrm{~mL}$ of cooled $\left(0^{\circ} \mathrm{C}\right) \mathrm{H}_{2} \mathrm{SO}_{4}$, and then $8 \mathrm{~g} \mathrm{KMnO}_{4}$ and $1 \mathrm{~g} \mathrm{NaNO}_{3}$ were added gradually while stirring. The mixture was transferred to a $40^{\circ} \mathrm{C}$ water bath and stirred for 60 minutes. Deionized water $(250 \mathrm{~mL})$ was slowly added, and the temperature was increased to $98^{\circ} \mathrm{C}$. The mixture was maintained at $98^{\circ} \mathrm{C}$ for 30 minutes, and the reaction was terminated by the addition of $500 \mathrm{~mL}$ deionized water and $40 \mathrm{~mL} 30 \% \mathrm{H}_{2} \mathrm{O}_{2}$. The color of the mixture changed to brilliant yellow, indicating the oxidation of pristine Gt to GO. The mixture was then filtered and washed with diluted $\mathrm{HCl}$ to remove metal ions. Finally, the product was washed repeatedly with distilled water until $\mathrm{pH} 7$ was achieved, and the synthesized GO was sonicated for 60 minutes.

Reduction of GO was accomplished as described previously. ${ }^{23,32}$ Briefly, rGO was obtained from the reaction of C-phycocyanin with GO. In a typical reduction experiment, $10 \mathrm{~mL}$ C-phycocyanin $(10 \mathrm{mg})$ was added to $90 \mathrm{~mL}$ $1 \mathrm{mg} / \mathrm{mL}$ aqueous $\mathrm{GO}$; the mixture was stirred at $30^{\circ} \mathrm{C}$ for 12 hours. Subsequently, with a magnetic-stirrer heater, the rGO suspension was rotated at $400 \mathrm{rpm}$ at a temperature of $30^{\circ} \mathrm{C}$ for 30 minutes.

\section{Synthesis of rGO-Ag nanocomposite}

Synthesized rGO-Ag nanocomposites were prepared using C-phycocyanin. An aqueous solution of $100 \mathrm{mg} \mathrm{GO}$ and $5 \mathrm{mM} \mathrm{AgNO}_{3}$ were used as precursors for the rGO-Ag nanocomposites. Initially, $100 \mathrm{mg}$ GO was dispersed in $60 \mathrm{~mL}$ water by 60 minutes' sonication. The reaction mixture was then prepared in a $250 \mathrm{~mL}$ round-bottom flask by dissolving $5 \mathrm{mM} \mathrm{AgNO}_{3}$ in $30 \mathrm{~mL}$ water. To this solution, $60 \mathrm{~mL} \mathrm{GO}$ dispersion and $10 \mathrm{~mL}$ of aqueous $10 \mathrm{mg}$ were added, and the mixture was stirred at $60^{\circ} \mathrm{C}$ for 12 hours. After 12 hours, the reaction was stopped and the resultant mixture washed three times by centrifugation with water. The product was obtained as a black powder and used for further experiments. $\mathrm{GO}$, rGO, and rGO-Ag nanocomposites were characterized according to methods described previously. ${ }^{21}$

\section{Cell culture, cell viability, and measurement of LDH and ROS}

Human cervical cancer cells (HeLa CCL2) were obtained from the American Type Culture Collection (Manassas, VA, USA), cultured in Roswell Park Memorial Institute 1640 medium supplemented with 10\% fetal bovine serum and $1 \%$ penicillin-streptomycin, and maintained in a humidified incubator at $5 \% \mathrm{CO}_{2}$ and $37^{\circ} \mathrm{C}$. Cells were routinely grown in $100 \mathrm{~mm}$ plastic tissue-culture dishes (Nunc, Roskilde, Denmark) and harvested with a solution of trypsinEDTA while in a logarithmic phase of growth. WST-8 and LDH assays were performed as described previously. ${ }^{21}$ Cell-membrane integrity of the HeLa cells was evaluated 
by determining the activity of LDH leaking out of the cells, as per the manufacturer's instructions (in vitro toxicology assay kit) and also as described previously. ${ }^{21}$ Reactive oxygen species (ROS) were estimated according to a method described previously. ${ }^{21}$

\section{Cell-proliferation assay}

Cell proliferation was evaluated using the trypan blue assay, as described earlier. ${ }^{33}$ HeLa cells were plated in six-well plates $\left(10^{5}\right.$ cells per well) and incubated for 24 hours. Cis (5 $\mu \mathrm{M}), \mathrm{rGO}-A g N P s(1 \mu \mathrm{g} / \mathrm{mL})$, or a combination of Cis plus rGO-AgNPs was then added to the cells for 24 hours. Cells cultured in the medium without Cis or rGO-AgNPs were used as controls. At 24 hours later, cells were detached with $300 \mu \mathrm{L}$ trypsin-EDTA solution, and both adherent cells and cells in suspension were collected. The mixture of the supernatant and detached cells was centrifuged at 1,200 rpm for 5 minutes. The pellet was added to $700 \mu \mathrm{L}$ of trypan blue solution and dispersed. After 5 minutes of staining, cells were counted using a cytometer. Viable cells were unstained, whereas dead cells were stained in blue. Three independent experiments were performed in triplicate. Mean and standard deviation were calculated. Cell proliferation is expressed as the percentage of viable cells.

\section{Measurement of oxidative stress markers}

Oxidative stress markers, such as malondialdehyde (MDA), glutathione (GSH), SOD, and CAT, were assayed with reagents from various kits, according to each manufacturer's instructions. Briefly, the cells were cultured in $75 \mathrm{~cm}^{2}$ culture flasks and exposed to Cis, rGO-AgNPs, or a combination of both for 24 hours. The cells were harvested in chilled phosphatebuffered saline by scraping and washing twice with the saline at $4^{\circ} \mathrm{C}$ for 6 minutes at $1,500 \mathrm{rpm}$. The cell pellet was sonicated at $15 \mathrm{~W}$ for 10 seconds (three cycles) to obtain the cell lysate. The resulting supernatant was stored at $-70^{\circ} \mathrm{C}$ until analyzed.

\section{Measurement of mitochondrial membrane potential}

Briefly, cells were cultured in $75 \mathrm{~cm}^{2}$ culture flasks and exposed to Cis, rGO-AgNPs, or a combination of both for 24 hours. Mitochondrial membrane potential (MMP) was measured, as described previously, using a cationic fluorescent indicator (JC-1; Thermo Fisher Scientific). ${ }^{25}$

\section{TUNEL assay}

Apoptosis was examined in cells treated in all three groups for 24 hours using a DNA-fragmentation imaging kit (Hoffman-La Roche Ltd, Basel, Switzerland), following the manufacturer's instructions and also previously described methods. ${ }^{13}$

\section{Quantitative RT-PCR analysis}

Extraction and amplification of messenger RNA (mRNA) followed Zhang and Gurunathan. ${ }^{13}$ According to the manufacturer's instructions, total RNA was extracted from treated and untreated cells using a Dynabeads mRNA Direct kit (Thermo Fisher Scientific). Real-time quantitative reversetranscription polymerase chain reaction (qRT-PCR) was conducted using Vill7 (Applied Biosystems, OR, USA) and SYBR green as the double-stranded DNA-specific fluorescent dye (Thermo Fisher Scientific). Target gene-expression levels were normalized to GAPDH gene expression, which was unaffected by Cis, rGO-AgNPs, or Cis plus rGO-AgNP treatment. The real-time qRT-PCR primer sets are shown in Table 1. Real-time qRT-PCR was performed independently

Table I List of primers used for quantitative real-time polymerase chain reaction for analysis of apoptotic, antiapoptotic, and autophagy gene expression

\begin{tabular}{|c|c|c|c|}
\hline & Gene & Direction & Primers $\left(5^{\prime}-3^{\prime}\right)$ \\
\hline \multirow[t]{2}{*}{ I } & $B A X$ & Forward & GAG AGG TCT TTT TCC GAG TGG \\
\hline & & Reverse & GGA GGA AGT CCA ATG TCC AG \\
\hline \multirow[t]{2}{*}{2} & P53 & Forward & AGG AAA TTT GCG TGT GGA GTA T \\
\hline & & Reverse & TCC GTC CCA GTA GAT TAC CAC T \\
\hline \multirow[t]{2}{*}{3} & BAK & Forward & CTC AGA GTT CCA GAC CAT GTT G \\
\hline & & Reverse & CAT GCT GGT AGA CGT GTA GGG \\
\hline \multirow[t]{2}{*}{4} & CAS3 & Forward & CAT ACT CCA CAG CAC CTG GTT A \\
\hline & & Reverse & ACT CAA ATT CTG TTG CCA СCT T \\
\hline \multirow[t]{2}{*}{5} & CAS9 & Forward & ACT TTC CCA GGT TTT GTT TCC T \\
\hline & & Reverse & GAA ATT AAA GCA ACC AGG CAT C \\
\hline \multirow[t]{2}{*}{6} & $B C L 2$ & Forward & CTG AGT ACC TGA ACC GGC A \\
\hline & & $\operatorname{Rev}$ & GAG AAA TCA AAC AGA GGC CG \\
\hline \multirow[t]{2}{*}{7} & $P 21$ & & ATG TGG ACC TGT CAC TGT CTT G \\
\hline & & Reverse & CTT CCT CTT GGA GAA GAT CAG C \\
\hline \multirow[t]{2}{*}{8} & ATG3 & Forward & GTT GGA AAC AGA TGA GGC TAC C \\
\hline & & Reverse & TAG CCA AAC AAC CAT AAT CGT G \\
\hline \multirow[t]{2}{*}{9} & ATG5 & Forward & ACC AGT TTT GGG CCA TCA AT \\
\hline & & Reverse & GTG TGT GCA ACT GTC CAT CTG \\
\hline \multirow[t]{2}{*}{10} & ATG7 & Forward & AAG CAA GAG AAA GCT GGT CAT C \\
\hline & & Reverse & AGT AGC AGC CAA GCT TGT AAC C \\
\hline \multirow[t]{2}{*}{11} & ATGI7 & Forward & TGA AGG AAG CAG AAA CTG ATG A \\
\hline & & Reverse & TGC TAA GCC CAC CTG ATA ATT T \\
\hline \multirow[t]{2}{*}{12} & ATG6 & Forward & GAG CAA ATG AAT GAG GAT GAC A \\
\hline & & & CAC TCT TCA GCT CAT CAT CCA G \\
\hline \multirow[t]{2}{*}{13} & ATG 12 & & GCA GCT TCC TAC TTC AAT TGC T \\
\hline & & Reverse & CCA GCA GGT TCC TCT GTT CC \\
\hline \multirow[t]{2}{*}{14} & ATGIO & Forward & CTG AAG GAC ATA TGG GAA GGA G \\
\hline & & Reverse & GAG GTA GAT TCA GCC CAA CAA C \\
\hline \multirow[t]{2}{*}{15} & GAPDH & Forward & GAG TCA ACG GAT TTG GTC GT \\
\hline & & Reverse & TTG ATT TTG GAG GGA TGT CG \\
\hline
\end{tabular}


in triplicate for each of the different samples, and data are presented as mean values of gene-expression levels measured in the treated samples versus the controls.

\section{Statistical analysis}

All assays were conducted in triplicate, and each experiment was repeated at least three times. The results represent the means of at least three independent experiments (mean \pm standard deviation). Student's $t$-test or one-way analysis of variance, followed by Tukey's test for multiple comparisons, were calculated, using GraphPad Prism software (GraphPad Software, San Diego, CA, USA). Differences were considered significant at $P<0.05$.

\section{Results and discussion Synthesis and characterization of GO, rGO,AgNPs, and rGO-AgNPs}

GO was prepared by a modified Hummers method by oxidation of Gt powder with strong oxidizers. ${ }^{34}$ Synthesized GO exhibits two characteristic peaks at 231 and $300 \mathrm{~nm}$, corresponding to the $\pi-\pi *$ transitions of aromatic $\mathrm{C}-\mathrm{C}$ bonds and $\mathrm{n}-\pi^{*}$ transitions of $\mathrm{C}=\mathrm{O}$ bonds, respectively. ${ }^{31}$ Ultraviolet (UV)-visible spectra of aqueous GO dispersions are presented in Figure 1A. Two different characteristic features were observed in these spectra to identify GO. The first was a shoulder at $\sim 300 \mathrm{~nm}$, corresponding to an $\mathrm{n}-\pi^{*}$ plasmon peak. The shoulders observed for all of the samples were similar. Another characteristic feature appeared at $231 \mathrm{~nm}$, and corresponds to a $\pi-\pi^{*}$ plasmon peak. The prepared GO was reduced by C-phycocyanin. The UV-visible spectrum of rGO exhibited a characteristic band at $263 \mathrm{~nm}$, indicating the restoration of the extensive conjugated $\mathrm{sp}^{2}$ carbon network. ${ }^{22,31}$ However, during reduction from GO to rGO, the characteristic absorption band at $300 \mathrm{~nm}$ disappeared and the absorption band at $263 \mathrm{~nm}$ observed in the rGO spectrum, which confirms the reduction of GO and the partial restoration of the $\pi$ network of rGO (Figure 1B).

Next, extracellular synthesis of AgNPs was carried out using C-phycocyanin with $5 \mathrm{mM} \mathrm{AgNO}_{3}$ aqueous solution. Reduction of the silver ion to AgNPs was observed by a
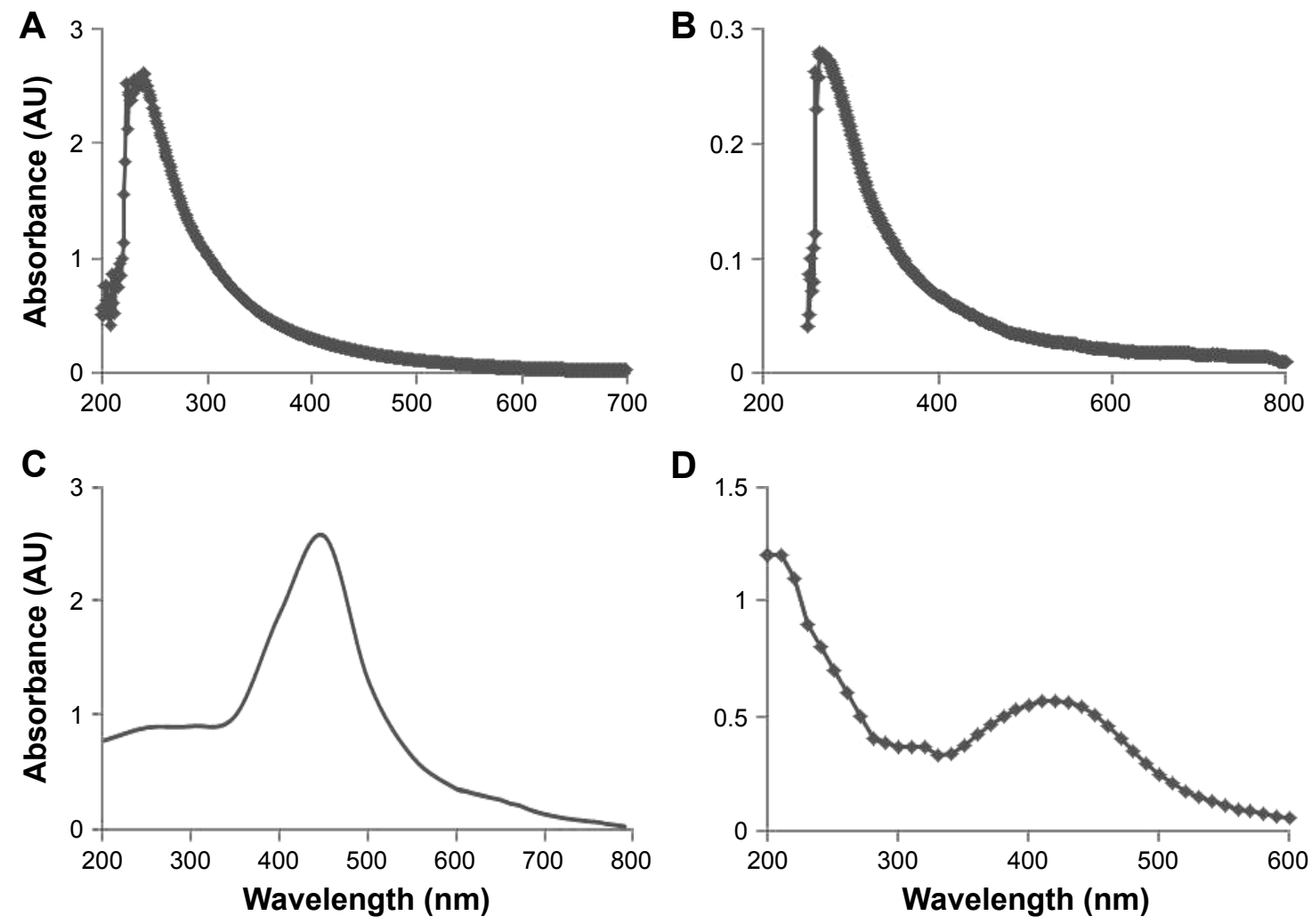

D

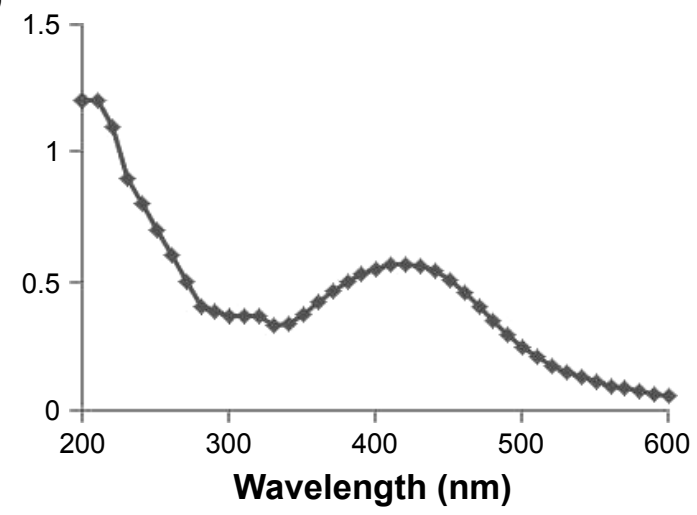

Figure I Characterization of GO, rGO, AgNPs, and rGO-AgNP nanocomposites using ultraviolet-visible spectroscopy.

Notes: (A) Spectra of GO exhibited a maximum absorption peak at $\sim 23 \mathrm{Imm}$, corresponding to the $\pi-\pi$ transitions of aromatic $\mathrm{C}-\mathrm{C}$ bonds. (B) The absorption peak for rGO was red-shifted to $263 \mathrm{~nm}$. (C) The absorption spectrum of AgNPs synthesized by C-phycocyanin exhibited a strong broad peak at 420 nm, which was assigned to surface plasmon resonance of the NPs. (D) A new peak at $420 \mathrm{~nm}$ was observed after deposition of AgNPs on the rGO surface; the band at $420 \mathrm{~nm}$ in the absorption spectrum of the rGO-AgNP nanocomposite was attributed to surface plasmons and the presence of AgNPs. At least three independent experiments were performed for each sample, and reproducible results were obtained. The data show the results of a representative experiment.

Abbreviations: rGO, reduced graphene oxide; NPs, nanoparticles. 
dark-brown appearance, which is the characteristic feature of AgNPs (Figure 1C). Figure 1C shows the UV-visible spectrum of AgNP formation and the change in the color of the reaction mixture to dark brown, indicating the biofabrication of ionic silver to reduced silver and the subsequent formation of AgNPs in an aqueous medium. ${ }^{30}$ Finally rGO-AgNPs were prepared by mixing of GO dispersion with C-phycocyanin as a reducing and stabilizing agent in the presence of $5 \mathrm{mM}$ AgNPs at $60^{\circ} \mathrm{C}$ for 12 hours. The nanocomposite containing both rGO and AgNPs showed characteristic peaks at 263 and $420 \mathrm{~nm}$. A new peak at $420 \mathrm{~nm}$ was observed after the deposition of AgNPs on the rGO surface (Figure 1D); the band at $420 \mathrm{~nm}$ in the absorption spectrum of the rGO-AgNP nanocomposite was attributed to surface plasmons and indicated the presence of AgNPs. ${ }^{21,30}$ The prepared nanocomposite was consistent with earlier reports that have used biomolecules as a template, such as plant extracts from Pulicaria glutinosa and Tilia amurensis, as reducing and stabilizing agents for synthesis of rGO-AgNPs. ${ }^{21,35}$

\section{XRD analysis of $r G O-A g N P s$}

Generally, pristine Gt has a strong and sharp diffraction peak at $2 \theta=26.38^{\circ}$, corresponding to the highly organized layer structure, with an interlayer distance of $0.34 \mathrm{~nm}$ along the (002) orientation. ${ }^{36}$ After reduction of Gt by an oxidizer, a strong peak was observed at $2 \theta=11.70^{\circ}$. Figure $2 \mathrm{~A}$ shows the X-ray diffraction (XRD) patterns of the GO. The (002) peak shift to a lower angle at $2 \theta=11.7^{\circ}$ after the chemical oxidation and exfoliation of Gt into GO, however, indicated an increase in d-spacing from $0.34 \mathrm{~nm}$ to $0.76 \mathrm{~nm}$. An increased interlayer distance between consecutive carbon basal planes was attributed to the intercalation of oxygen functional groups and water molecules into a carbon-layer structure. ${ }^{36,37}$ The characteristic peak (002) of Gt at $26.58^{\circ}$ disappeared after oxidation, while an additional peak at $11.7^{\circ}$ was observed (Figure $2 \mathrm{~A}$ ), which corresponded to the (001) diffraction peak of GO. ${ }^{22}$ rGO showed a broad peak that could be fitted by using a Lorentzian function into single broad peaks centered at $25.88^{\circ}$, corresponding to interlayer

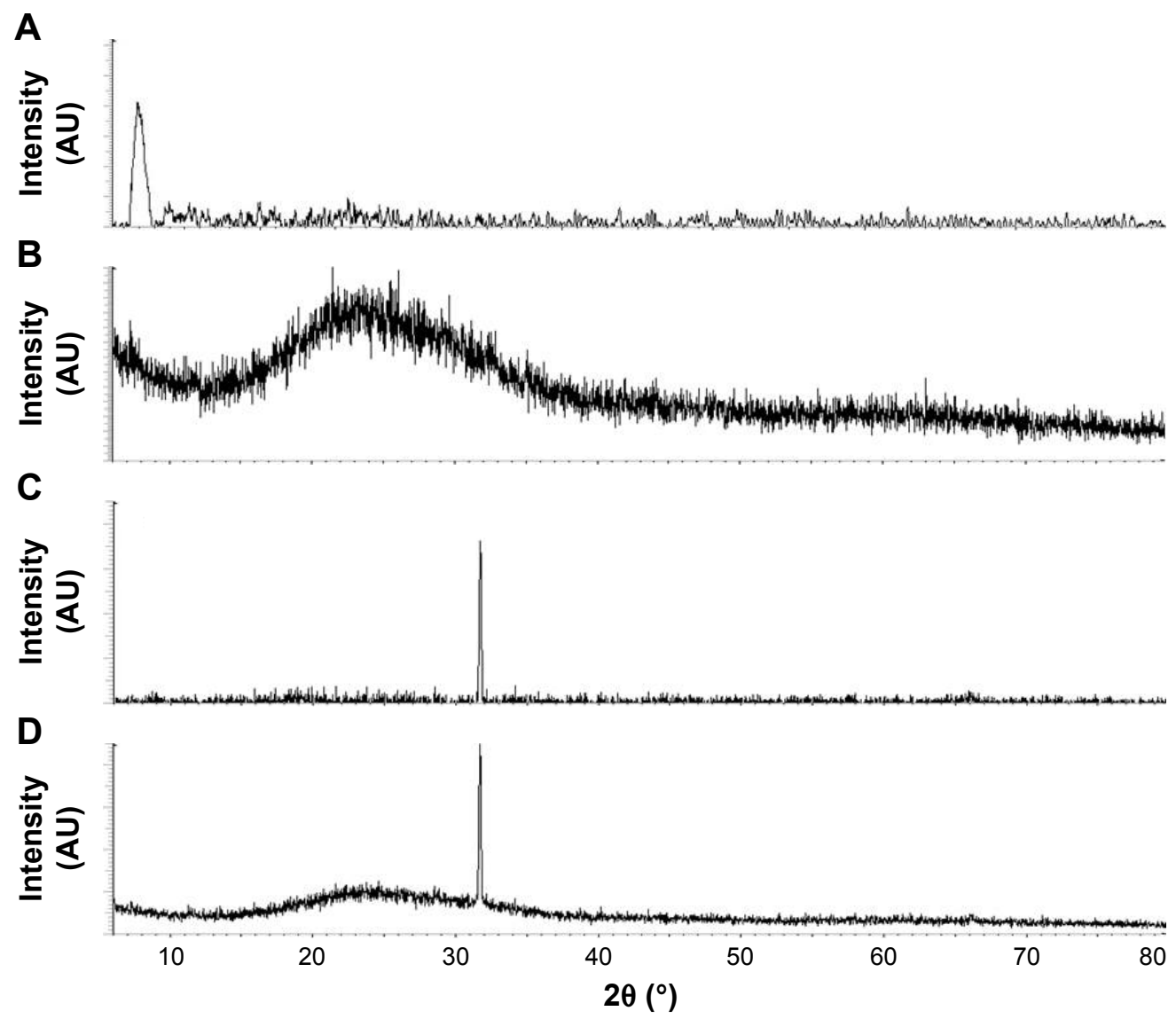

Figure 2 X-ray diffraction (XRD) patterns of GO, rGO, AgNPs, and rGO-AgNP nanocomposites.

Notes: $(\mathbf{A})$ In the XRD pattern of $G O$, a strong sharp peak at $2 \theta=11.7^{\circ}$ corresponded to an interlayer distance of $7.6 \AA$. (B) rGO had a broad peak centered at $2 \theta=25.88^{\circ}$, corresponding to an interlayer distance of $3.6 \AA$. Apart from the characteristic reflections of $r G O\left(2 \theta=25.88^{\circ}\right)$. (C) AgNPs showed distinct reflections in the diffractogram at $32.8^{\circ}$, corresponding to the (III) planes. (D) rGO-AgNPs showed two different distinct reflections in the diffractogram at $25.88^{\circ}$, corresponding to rGO, and $32.8^{\circ}$, corresponding to the (III) planes of face-centered cubic Ag. At least three independent experiments were performed for each sample, and reproducible results were obtained. The data show the results of a representative experiment.

Abbreviations: rGO, reduced graphene oxide; NPs, nanoparticles. 
distances of $3.53 \AA$. The rGO exhibited a new broad peak at $25.88^{\circ}$, corresponding to the $\mathrm{d}$-spacing of $0.38 \mathrm{~nm}$ along the (002) orientation (Figure 2B), which was due to the removal of oxygen functional groups, causing a decrease in d-spacing. Altogether, these XRD results confirmed the exfoliation and reduction processes of $\mathrm{GO}$ and the processes of removing intercalated water molecules and the oxide groups.

Next, we confirmed the crystalline nature of AgNPs using XRD. The XRD pattern of the synthesized AgNPs is shown in Figure $2 \mathrm{C}$. The diffracted intensities were recorded from $20^{\circ}$ to $80^{\circ}$. One strong Bragg reflection at $32.8^{\circ}$ corresponded to the planes of (111), which can be indexed according to the facets of the face-centered cubic crystal structure of silver. ${ }^{21}$ Finally, we confirmed the crystalline nature of nanocomposites containing graphene and silver using XRD. As shown in Figure 2D, the nanocomposites exhibited two characteristic peaks at $25.88^{\circ}$ and $32.8^{\circ}$, corresponding to rGO and AgNPs, which indicated that the nanocomposites contains both nanomaterials in a single platform and also confirming that $\mathrm{Ag}$ existed in a crystalline state. ${ }^{21,28}$ The purity of peaks represented by graphene and Ag clearly indicated the reduction of $\mathrm{GO}$ and $\mathrm{Ag}$ ions, and suggested that the
rGO-AgNP nanocomposite lattice was unaffected by other molecules in C-phycocyanin.

\section{FTIR analysis of rGO-AgNPs}

Fourier-transform infrared (FTIR) spectroscopy was performed to determine chemical bonding in the newly synthesized nanomaterials. FTIR spectra of GO are shown in Figure 3A. The FTIR spectra of the GO sample accorded well with previously published reports, ${ }^{38-40}$ showing various oxygen configurations. An intense and broad peak appeared at around $3,440 \mathrm{~cm}^{-1}$, assigned to the stretching mode of an $\mathrm{O}-\mathrm{H}$ bond, revealed the abundance of hydroxyl groups in $\mathrm{GO} .{ }^{38}$ The strong bands at $2,360 \mathrm{~cm}^{-1}, 1,750 \mathrm{~cm}^{-1}$, and $1,640 \mathrm{~cm}^{-1}$ exhibited the presence of $(\mathrm{O}-\mathrm{C}=\mathrm{O}),(\mathrm{C}=\mathrm{O})$, and $(\mathrm{OH}$ bending) functional groups in $\mathrm{GO}$, and bands at $1,290 \mathrm{~cm}^{-1}$ and $1,100 \mathrm{~cm}^{-1}$ were attributed to the presence of $(\mathrm{C}-\mathrm{OH})$ and $(\mathrm{C}-\mathrm{O})$ (epoxy) groups, respectively. ${ }^{38}$ As shown in Figure 3B, the spectra of rGO indicated that the oxygen-functionality band was significantly reduced by biological reduction. Characteristic bands at $1,290 \mathrm{~cm}^{-1}$ and $1,100 \mathrm{~cm}^{-1}$ were attributed to the presence of $(\mathrm{C}-\mathrm{OH})$ and $(\mathrm{C}-\mathrm{O})$, such as carboxyl/carbonyl, epoxy, and alkoxy,

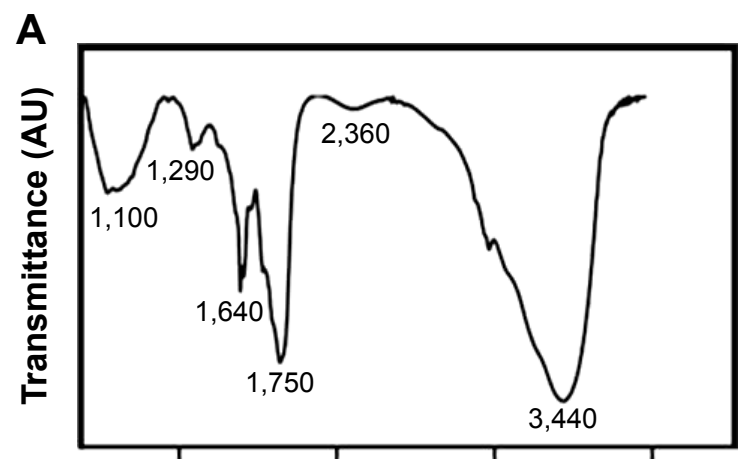

B
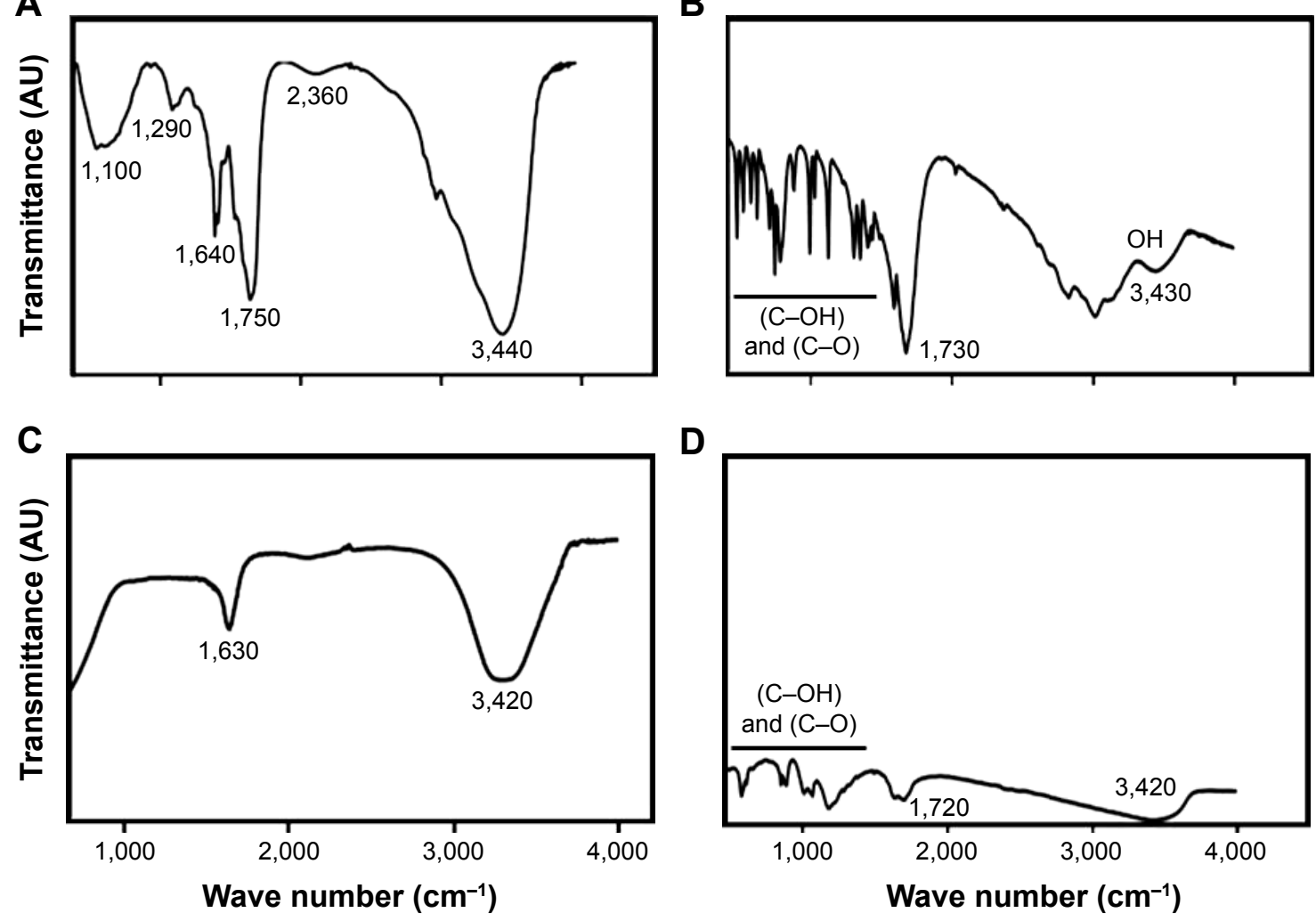

Figure 3 Fourier-transform infrared (FTIR) spectra of GO, rGO, AgNPs, and rGO-AgNP nanocomposites.

Notes: Dried powders of (A) GO, (B) rGO, (C) AgNPs, and (D) rGO-AgNPs were diluted with KBr to perform FTIR spectroscopy, and spectra were obtained using GX spectrometry within the range of $500-4,000 \mathrm{~cm}^{-1}$.

Abbreviations: rGO, reduced graphene oxide; NPs, nanoparticles. 
and were significantly decreased. ${ }^{23}$ After GO reduction by C-phycocyanin, all the characteristic absorption bands of oxygen-containing groups $(\mathrm{O}-\mathrm{H}, \mathrm{C}=\mathrm{O}$, and $\mathrm{C}-\mathrm{O})$ were substantially weakened. The spectra of AgNPs is shown in Figure 3C, a typically characteristic band of AgNPs observed at $3,420 \mathrm{~cm}^{-1}$ corresponded to $\mathrm{O}-\mathrm{H}$ stretching vibration, indicating the presence of an alcohol and phenol band at $1,630 \mathrm{~cm}^{-1}$ in the spectra corresponding to $\mathrm{C}-\mathrm{N}$ and $\mathrm{C}-\mathrm{C}$ stretching, indicating the presence of proteins. FTIR spectra of rGO-AgNPs was similar to $\mathrm{rGO}$, with weaker intensity and a small shift toward low wave numbers, which was due to the presence of large amounts of AgNPs. The intensity of the $\mathrm{OH}, \mathrm{C}-\mathrm{OH}$, and $\mathrm{C}-\mathrm{O}$ bands strongly decreased, and the $\mathrm{C}=\mathrm{O}$ bond disappeared. This indicated that many oxygen groups were removed during the transformation of $\mathrm{GO}$ to rGO (Figure 3D). FTIR spectra of rGO-AgNPs from this work accorded well with environment-friendly plant extract and L-arginine-mediated synthesis of rGO-AgNPs. ${ }^{21}$

\section{Surface and morphology analysis of rGO-AgNPs}

Transmission electron microscopy (TEM) is an important and frequently used technique for the characterization of newly synthesized nanomaterials, such as for particle and/or grain size, size distribution, and morphology..$^{13}$ GO was formed by heavily oxidizing Gt to exfoliate chemically the flakes of the graphitic stack into mono- and multiple-layer sheets. ${ }^{41}$ The morphological features of GO, rGO, AgNPs, and $\mathrm{rGO}-\mathrm{AgNPs}$ were determined by TEM analysis. Figure 4 shows typical TEM images of GO, rGO, AgNPs, and rGOAgNPs; GO exhibited a closely packed lamellar and plate structure with a clean surface (Figure 4A), which was consistent with previously prepared $\mathrm{GO} .{ }^{21}$ In contrast to GO, rGO showed typical sheet-like silky waves, wrinkled appearance, and clumped structure with a size of 20-100 nm (Figure 4B). AgNPs were typically spherical and significantly uniform in size, with average size of $10 \mathrm{~nm}$ (Figure 4C). Interestingly, the
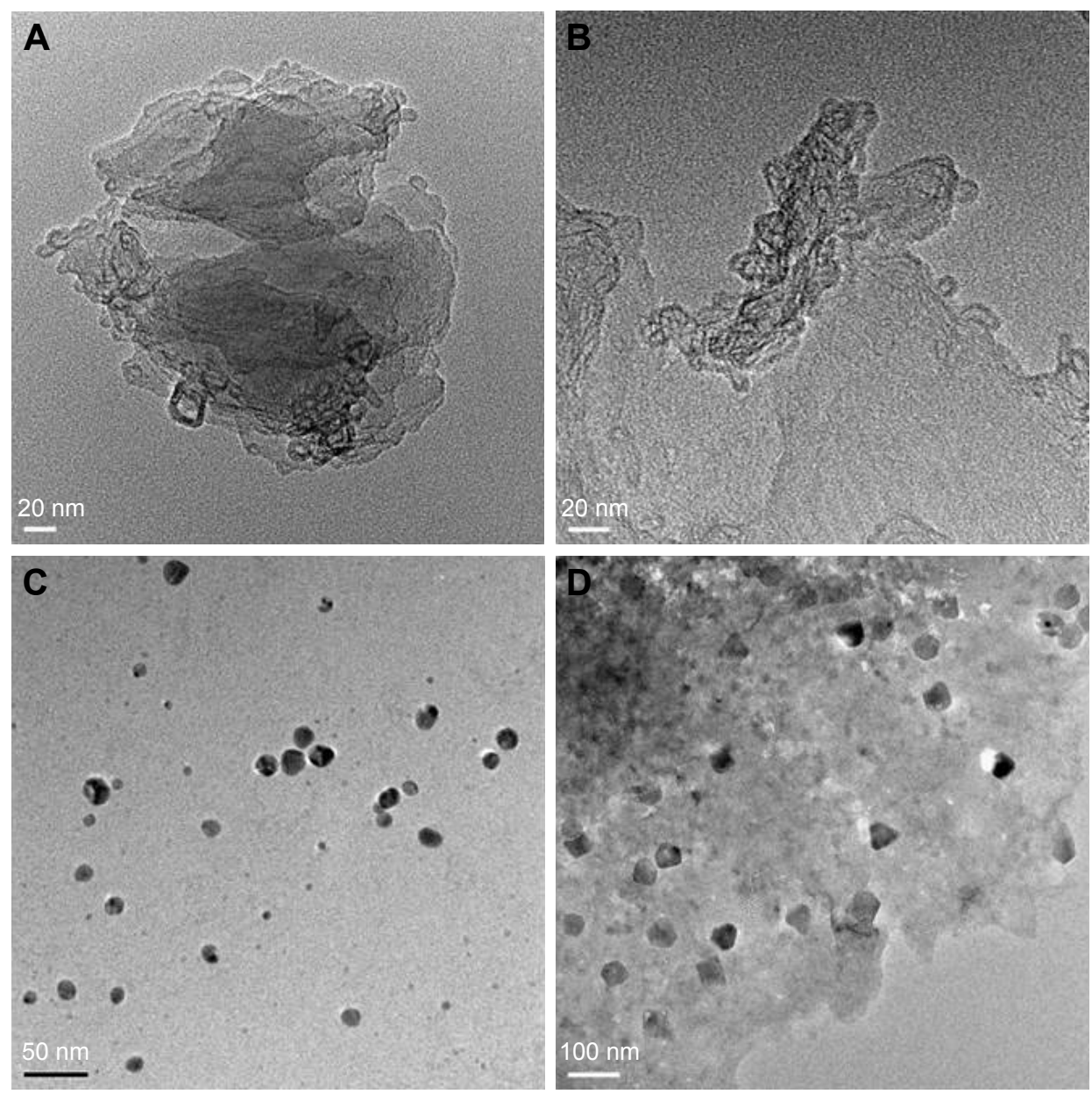

Figure 4 Transmission electron microscopy (TEM) images of GO, rGO, AgNPs, and rGO-Ag nanocomposites.

Notes: TEM studies of the (A) GO, (B) rGO, (C) AgNPs, and (D) rGO-AgNPs were carried out on a Hitachi H-7500, operating at $200 \mathrm{kV}$.

Abbreviations: rGO, reduced graphene oxide; NPs, nanoparticles. 
rGO-AgNPs showed many AgNPs anchored to the surfaces of rGO sheets. The adhered NPs had spherical morphology, an even distribution, and a homogeneous dispersion on the $\mathrm{rGO}$ surfaces; most NPs had a diameter of $10 \mathrm{~nm}$. In addition, the presence of evenly distributed silky waves, a characteristic feature of rGO sheets, was observed. ${ }^{21}$ The TEM image of the rGO-AgNPs clearly indicates strong interactions between the AgNPs and rGO, because almost all AgNPs were distributed within the rGO sheet. ${ }^{21,42}$ The results obtained from this study are consistent with previously synthesized nanocomposites. For instance, Shen et al reported a solution-based synthesis of AgNPs in chemically converted graphene using a mixed reducing agent, and found a homogeneous distribution of AgNPs of size 5-10 nm on chemically converted graphene. ${ }^{43}$ GO nanosheets were impregnated with AgNPs by the in situ reduction of adsorbed $\mathrm{Ag}^{+}$by hydroquinone in a citrate buffer solution, and prepared GO-AgNPs showed a transparent, single-layer, paper-like structure in which AgNPs were homogeneously arranged on the micron scale of the GO. ${ }^{44}$ Chemically mediated GO-Ag nanosheets showing AgNPs anchored on the surface of transparent silk waves of the GrO sheets indicated that the AgNPs were deposited on the GO-suspension support. ${ }^{45}$ Yang et al observed that the surface of GO sheets was modified by AgNPs using tryptophan as a reducing and stabilizing agent for synthesis of $\mathrm{GO}-\mathrm{Ag}$ nanosheets. ${ }^{46}$ Gelatin-mediated synthesis of GO and AgNPs showed silver nanoprisms deposited on the surface of the transparent sheets were flake-like, with wrinkled structures of transparent sheets. ${ }^{47}$ The C-phycocyanin-stabilized AgNPs exhibited spherical-like morphology, with an average size of $10 \pm 3 \mathrm{~nm}$, whereas AgNPs attached to the rGO surface were spherical and well dispersed throughout the sheets and presented no evidence of agglomeration. Also, all particles were attached to rGO surface, and there was none found unattached from the rGO sheet (Figure 4D). The nanocomposite exhibited AgNPs with an average size of $15.3 \pm 3.7 \mathrm{~nm}$, which was slightly larger than AgNPs alone. Altogether, these data confirmed that the surface of rGO sheets was modified by the nanosized AgNPs. Most of the synthesized AgNPs absorbed on the rGO sheet exhibited spherical shape, which displayed a significant combination between AgNPs and rGO.

\section{Effect of GO, rGO, AgNPs, and rGO-AgNPs on viability of HeLa cells}

Investigation of the cytotoxic efficiency of newly synthesized nanomaterials is an important factor in toxicological assays. Therefore, we evaluated the effect of all prepared nanomaterials - GO, rGO, AgNPs, and rGO-AgNPs - on the viability of HeLa cells. Cells were treated with various types of nanomaterials at different concentrations: $\mathrm{GO}$ 20-100 $\mu \mathrm{g} / \mathrm{mL}$, rGO $10-50 \mu \mathrm{g} / \mathrm{mL}$, AgNPs 5-25 $\mu \mathrm{g} / \mathrm{mL}$, and rGO-AgNPs $0.1-6 \mu \mathrm{g} / \mathrm{mL}$. Figure 5 shows the results of the cell-viability analysis. A dose-dependent inhibition of cell viability was observed with $\mathrm{GO}$ in the range of 20-100 $\mu \mathrm{g} / \mathrm{mL}$, with a half-maximal inhibitory concentration $\left(\mathrm{IC}_{50}\right.$ ) of $\sim 55 \mu \mathrm{g} / \mathrm{mL}$ (Figure $5 \mathrm{~A}$ ). With rGO, a dose-dependent inhibition of cell viability was observed in the range of $10-50 \mu \mathrm{g} / \mathrm{mL}$, with an $\mathrm{IC}_{50}$ of $\sim 15 \mu \mathrm{g} / \mathrm{mL}$ (Figure 5B). Dose-dependent inhibition of cell viability was observed with AgNPs in the range of $10-50 \mu \mathrm{g} / \mathrm{mL}$, with an $\mathrm{IC}_{50}$ of $\sim 15 \mu \mathrm{g} / \mathrm{mL}$ (Figure $5 \mathrm{C}$ ). With rGO-AgNPs, dose-dependent inhibition of cell viability was observed in the range of $0.1-6 \mu \mathrm{g} / \mathrm{mL}$, with an $\mathrm{IC}_{50}$ of $\sim 1.5 \mu \mathrm{g} / \mathrm{mL}$ (Figure 5D). rGO-AgNPs had a more pronounced inhibitory effect on cell viability than the other nanomaterials tested. A previous study has shown that GO is less toxic than rGO. For example, when LNCaP prostate cancer cells treated with glucose reduced $\mathrm{GO}$, the activity of the transparent GO sheets was not as effective as that of the rGO produced through glucose reduction in the presence of an Fe catalyst. ${ }^{48}$ Similarly, bacterially reduced nanographene sheets induce more toxicity than GO in human breast cancer cells. ${ }^{22}$ Plant extract-mediated GO-AgNPs showed significant toxicity in human ovarian cancer cells over other nanomaterials, including GO, rGO, and AgNPs. Recently, de Luna et al assessed the cytotoxicity of a GO-Ag nanocomposite, pristine GO, and pristine AgNPs in two representative murine macrophages: a tumoral lineage (J774) and peritoneal macrophages collected from $\mathrm{BALB} / \mathrm{c}$ mice. ${ }^{49}$ The results from their study suggested that the $\mathrm{GO}-\mathrm{Ag}$ nanocomposite was more toxic than pristine GO and pristine AgNPs for both macrophages, and it significantly induced more ROS production compared to pristine AgNPs. ${ }^{49}$ Altogether, the results suggested that rGO-AgNPs are a promising material for inhibiting the viability of cervical cancer cells. Therefore, we chose only rGO-AgNPs for further experiments.

\section{Cytotoxic effects of $\mathrm{Cis}$ and oxaliplatin in HeLa cells}

In order to study the combination effect of rGO-AgNPs with anticancer drugs, we selected $\mathrm{C}$ is and oxaliplatin (OHP) with concentrations of 2.5-20 $\mu \mathrm{M}$. Cell viability was determined by WST assay. HeLa cells were treated with various concentrations of Cis and OHP. Treatment of these cells tested with Cis and OHP resulted in dose-dependent inhibition of cell growth; however Cis showed significantly 

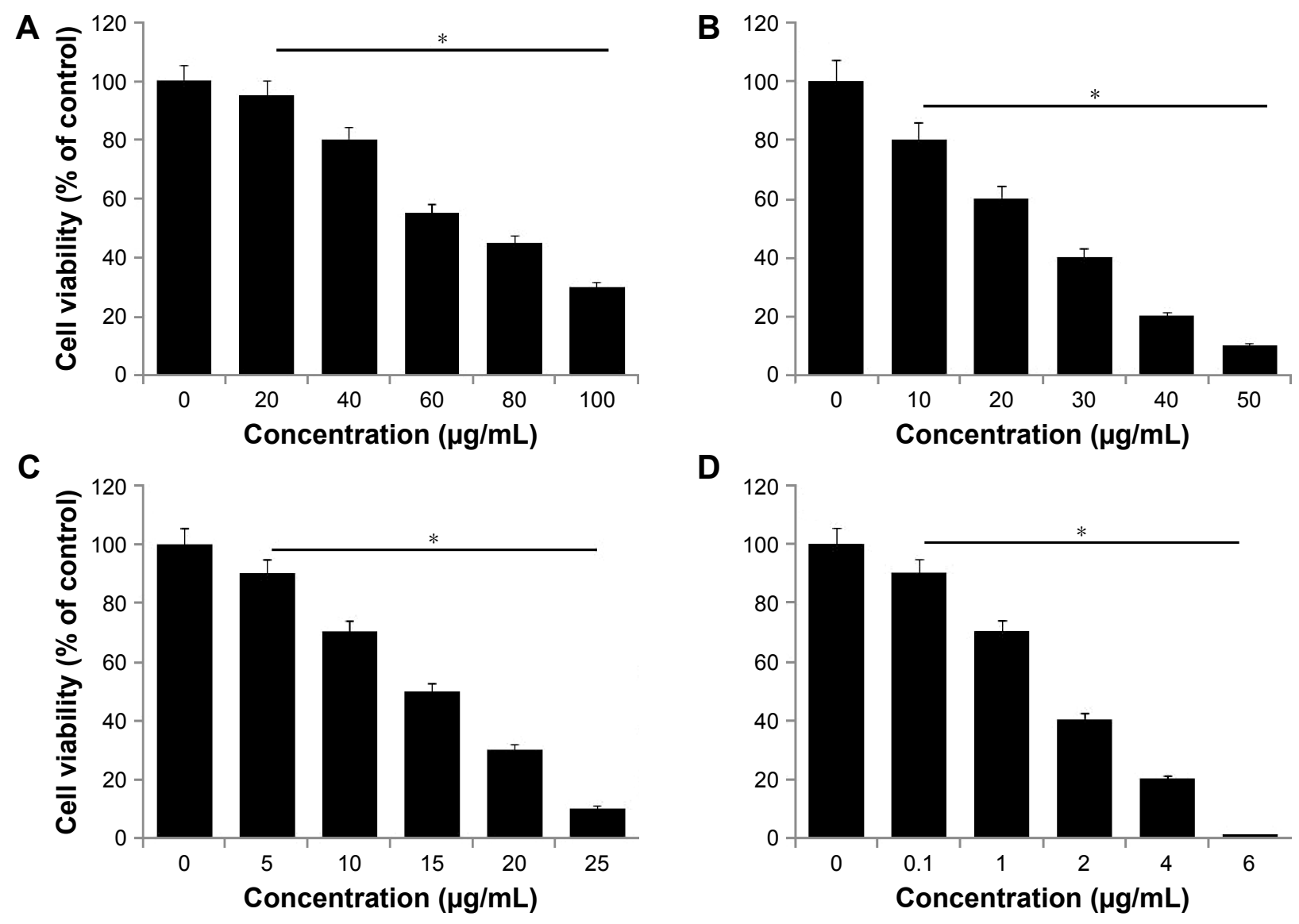

Figure 5 Effects of GO, rGO, AgNPs and rGO-Ag nanocomposites on the viability of HeLa cells.

Notes: The viability of HeLa cells was determined after 24-hour exposure to different concentrations of (A) GO, (B) rGO, (C) AgNPs, and (D) rGO-AgNPs using the WST-8 assay. Results are expressed as mean \pm standard deviation of three independent experiments. A significant difference was observed in each treated sample. The viability of treated cells was compared to untreated cells with Student's $t$-test $(* P<0.05)$.

Abbreviations: $r G O$, reduced graphene oxide; NPs, nanoparticles.

higher toxicity than OHP. With Cis, a dose-dependent inhibition of cell viability was observed at 2.5-20 $\mu \mathrm{M}$, with an $\mathrm{IC}_{50}$ of $\sim 10 \mu \mathrm{M}$ (Figure $6 \mathrm{~A}$ ), whereas OHP showed an $\mathrm{IC}_{50}$ of $12.5 \mu \mathrm{M}$ (Figure $6 \mathrm{~B}$ ). The activity of both drugs appeared to show a slightly dose-dependent effect of drug concentrations used, and the inhibitory activity of Cis was higher than that of OHP at every concentration and seemed meagerly modulated by increasing drug concentration. Similarly, Cis showed slightly higher toxicity when A431 cells were treated with different concentrations than OHP. Among these two different cytotoxic agents, Cis showed a more pronounced effect than OHP. Therefore, we selected only $\mathrm{C}$ is for further experiments.

\section{Combination effect of $\mathrm{Cis}$ and rGO-AgNPs in HeLa cells}

Combination therapy containing $\mathrm{Cis}$ has received much interest in cancer therapy. Although platinum-based therapy has received much attention, ultimately it leads to relapse with Cis-resistant diseases. As such, the combination of Cis with nanomaterials offers an alternative therapy for cancer. We were interested in studying the combination effect of Cis and rGO-AgNPs. The effective combined cytotoxic dose was examined by simultaneously adding Cis $(2.5-20 \mu \mathrm{M})$ and a fixed concentration of rGO-AgNPs $(1 \mu \mathrm{g} / \mathrm{mL})$ to HeLa cells. The results showed that increasing concentrations of $C$ is with rGO-AgNPs significantly reduced cell viability compared to singular treatment (Figure 7A). Similarly, we examined a combination of increasing concentrations of rGO-AgNPs $(0.1-6 \mu \mathrm{g} / \mathrm{mL})$ and a fixed concentration of $\mathrm{Cis}(5 \mu \mathrm{M})$. The results suggested that increasing concentration of $\mathrm{Cis}$ significantly enhances the combination effect with rGO-AgNPs, which was comparable to the effect of increasing rGO-AgNP concentration. Notably, an increased concentration of rGOAgNPs from 0.1 to $6 \mu \mathrm{g} / \mathrm{mL}$ in combination with $5 \mu \mathrm{M}$ Cis significantly inhibited HeLa cell growth (Figure 7B) at the lowest concentration. The higher concentration of $\mathrm{Cis}$ and rGO-AgNPs caused a higher cytotoxic effect; therefore, we 

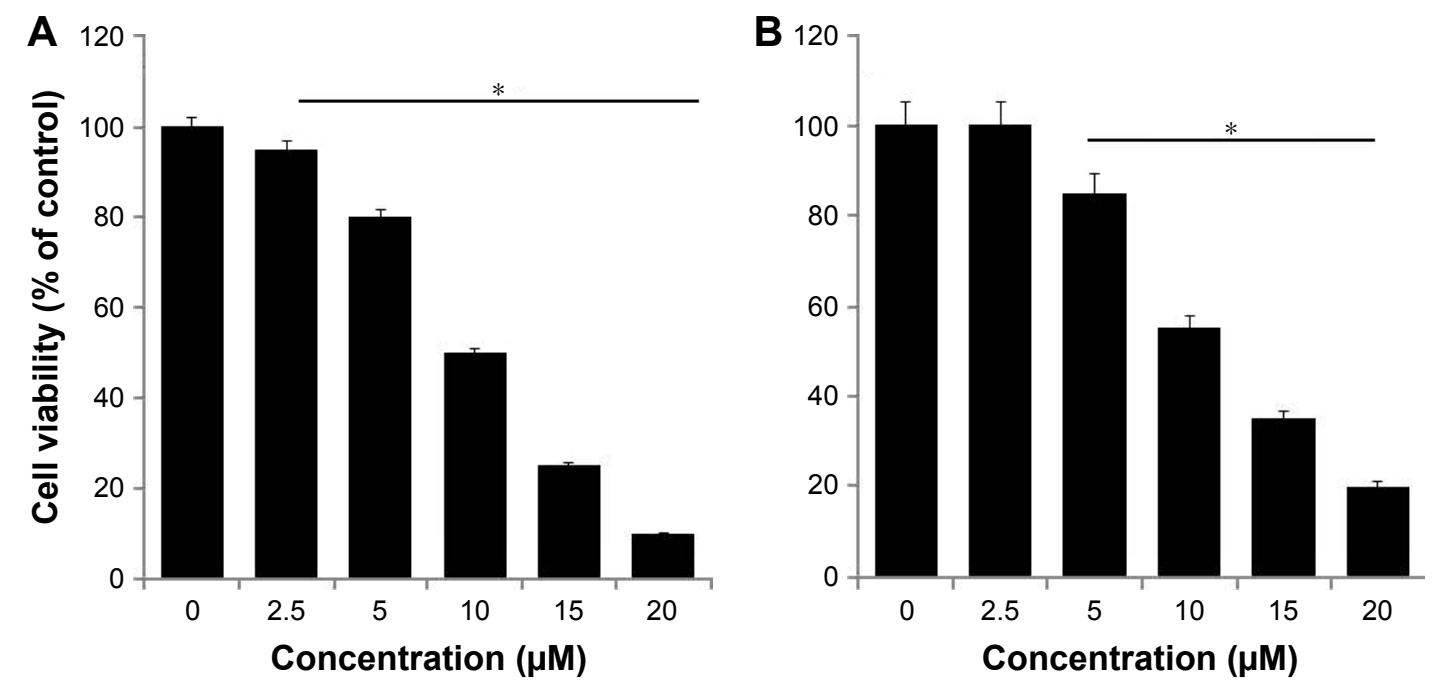

Figure 6 Effect of Cis and OHP on cell viability of HeLa cells.

Notes: The viability of HeLa cells was determined after 24-hour exposure to different concentrations of (A) Cis and (B) OHP using the WST-8 assay. Results are expressed as mean \pm standard deviation of three independent experiments. A significant difference was observed above $50 \mu$ M. The viability of treated cells was compared to untreated cells with Student's $t$-test $(* P<0.05)$.

Abbreviations: Cis, cisplatin; OHP, oxaliplatin; rGO, reduced graphene oxide; NPs, nanoparticles.

selected Cis $(5 \mu \mathrm{M})$ and rGO-AgNPs $(1 \mu \mathrm{M})$ for combination experiments. This was obviously a better strategy to improve the anticancer activity of either Cis or rGO-AgNPs in HeLa cells. Therefore, the remaining experiments were carried out in cells treated with a combination of Cis $(5 \mu \mathrm{M})$ and rGO$\operatorname{AgNPs}(1 \mu \mathrm{M})$, unless specified otherwise. Previous studies ${ }^{13}$ have reported that combination of AgNPs and salinomycin significantly inhibited cell viability and induced apoptotic and autophagy in human ovarian cells. A combination of trichostatin A and palladium NPs produced significant inhibitory effects in HeLa cells. So far, there has been no study to investigate the combination effect of Cis and rGOAgNPs in any kind of cancer cell lines. Furthermore, this approach is novel. Therefore, further experiments were
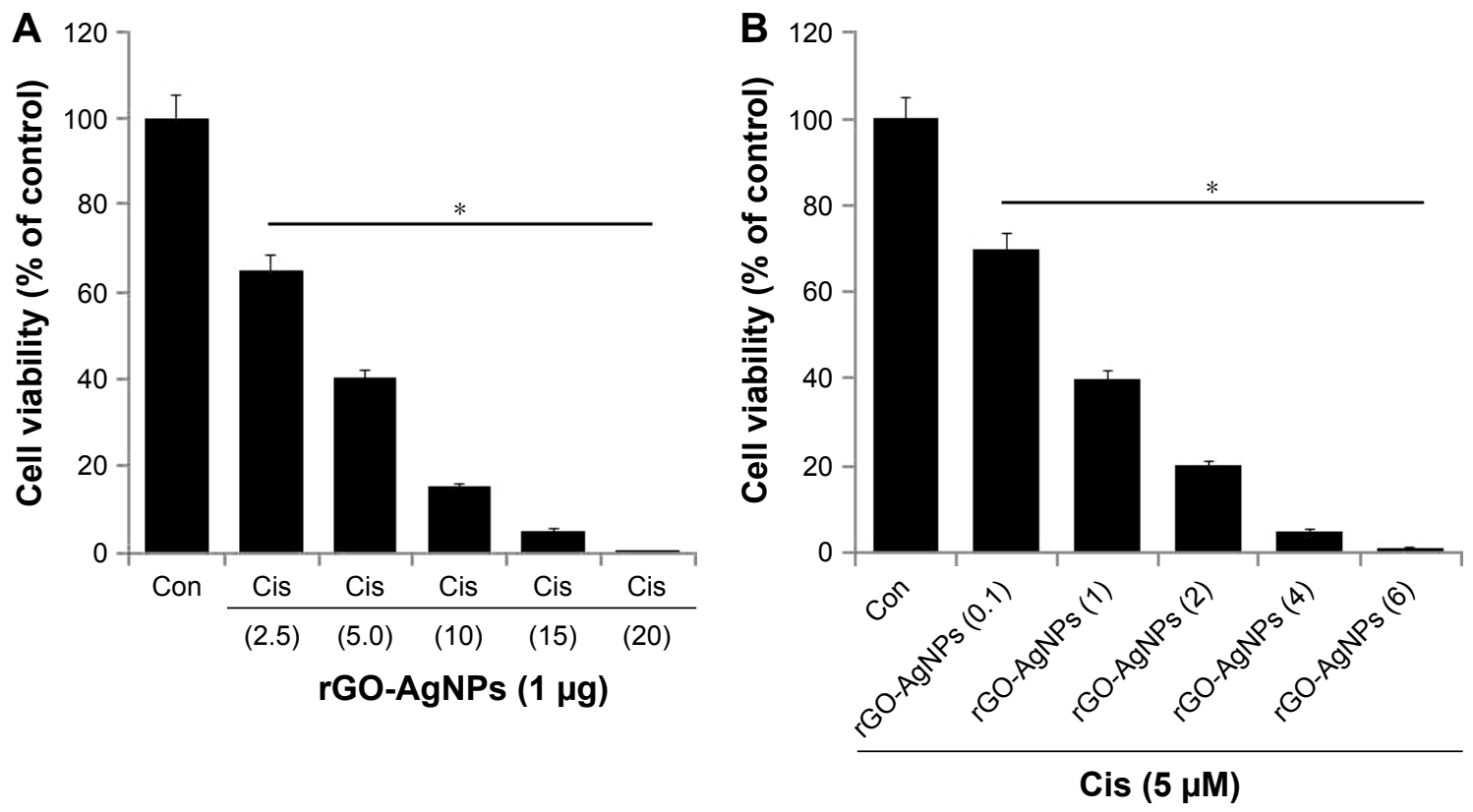

Figure 7 Increasing concentrations of Cis or rGO-AgNPs enhanced the loss of cell viability in HeLa cells.

Notes: (A) HeLa cells were coincubated for 24 hours with increasing concentrations of Cis ( 2.5 to $20 \mu \mathrm{M})$ and) rGO-AgNPs (I $\mu g / \mathrm{mL})$, (B) increasing concentrations of rGO-AgNPs $(0.1-6 \mu \mathrm{g} / \mathrm{mL})$, and $5 \mu \mathrm{M}$ Cis. Results are expressed as mean \pm standard deviation of three separate experiments. The treated groups showed statistically significant differences from the Con group, as determined by Student's $t$-test $(* P<0.05)$.

Abbreviations: Cis, cisplatin; rGO, reduced graphene oxide; NPs, nanoparticles; Con, control. 
performed on the combination effect of Cis and rGO-AgNPs in HeLa cells.

\section{Combination effect of $\mathrm{Cis}$ and rGO- $\mathrm{AgNPs}$ on cell viability and proliferation of HeLa cells}

The next series of experiments addressed the question of whether there would be a synergistic effect of Cis and rGOAgNPs on HeLa cell viability and proliferation. Therefore, HeLa cells were incubated with Cis $(5 \mu \mathrm{M})$ or rGO-AgNPs $(1 \mu \mathrm{g} / \mathrm{mL})$ for 24 hours, either alone or in combination. HeLa cells treated with Cis had a $25 \%$ decrease in cell viability compared to the untreated control, whereas rGO-AgNPs treatment resulted in a $30 \%$ decrease in cell viability compared to the untreated control. The viability of cells coincubated with Cis and rGO-AgNPs decreased by $70 \%$, compared to a $25 \%-30 \%$ decrease in cells treated with either Cis or AgNPs alone (Figure 8A). These results indicated a synergistic effect of Cis and AgNPs on HeLa cell cytotoxicity. Moreover, the lower concentrations of these two compounds would reduce the side effects; therefore, it is a better potential therapeutic approach to combine both reagents. It could be a novel and effective tool to kill cancer cells effectively in a time- and dose-dependent manner.

To evaluate the antiproliferative effects of the chemotherapeutic agent $\mathrm{Cis}(5 \mu \mathrm{M})$ or rGO-AgNPs $(1 \mu \mathrm{g} / \mathrm{mL})$ alone or in combination, we performed trypan blue assays. Cells were treated with the respective concentrations for 24 hours. Treatment with Cis alone inhibited 25\% and rGO-AgNPs

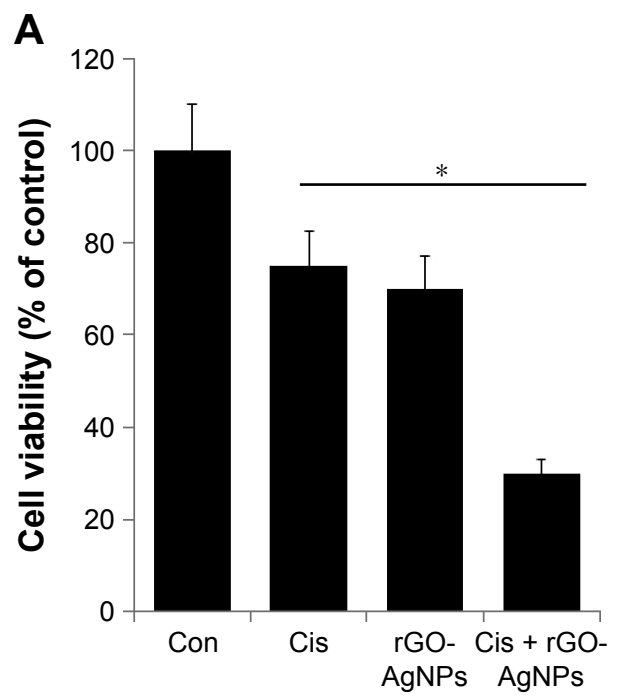

alone inhibited $30 \%$ of proliferation. The combination of Cis and rGO-AgNPs showed a pronounced antiproliferative effect up to $70 \%$ (Figure 8B). Cis and rGO-AgNPs showed similar trends in cell viability and proliferation. Cis-loaded poly(lactic-co-glycolic acid) NPs exhibit reduced side effects without compromising drug efficacy in tumor-bearing mice. ${ }^{50,51}$ Similarly, Cis conjugated to polyethylene glycolated single-walled carbon nanotubes is effective against head and neck tumor xenografts in mice. ${ }^{52}$ Altogether, the combination of Cis and rGO-AgNPs showed greater sensitivity than single treatment in HeLa cells. These data strongly suggest that the synergistic effect of rGO-AgNPs on enhancement of Cis-induced cytotoxicity was related to its inhibition of cell viability and proliferation of cells. According to cell-viability and cell-proliferation assays, Cis $(5 \mu \mathrm{M})$ or rGO-AgNPs $(1 \mu \mathrm{g} / \mathrm{mL})$ was chosen for further experiments.

\section{rGO-AgNPs enhance cytotoxic effect of Cis}

Chemotherapeutic agents are known to induce ROS levels in cancer cells. ${ }^{53}$ Also, recently we observed that both GO and AgNPs were capable of inducing ROS in several cancer cell lines..$^{21,22,32}$ Therefore, we were interested to investigate whether Cis, rGO-AgNPs, or a combination of Cis and rGO-AgNPs induced a dramatic effect on ROS-induced cell toxicity. To study the oxidative impact of Cis and rGOAgNPs on cellular oxidation-reduction (redox) state, we measured cellular ROS levels after exposing HeLa cells to Cis, rGO-AgNPs, or a combination of both for 24 hours.

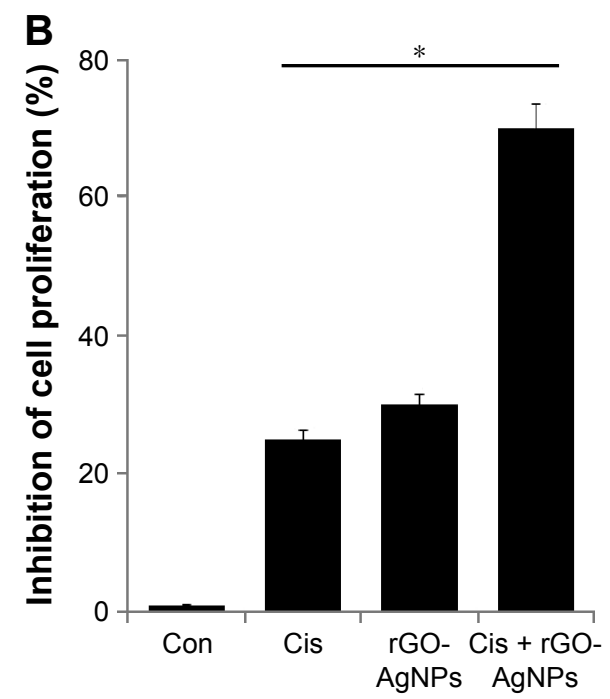

Figure 8 The effect of Cis or rGO-AgNPs alone or the combinatorial effect of Cis plus rGO-AgNPs on cell viability and proliferation in HeLa cells. Notes: HeLa cells were incubated with Cis $(5 \mu \mathrm{M})$ or rGO-AgNPs $(I \mu g / \mathrm{mL})$ or a combination of Cis plus rGO-AgNPs for 24 hours. (A) Cell viability was measured using WST-8. (B) Cell proliferation was measured by trypan blue assay. Treated groups showed statistically significant differences from the Con group, as determined by Student's $t$-test $(* P<0.05)$.

Abbreviations: Cis, cisplatin; rGO, reduced graphene oxide; NPs, nanoparticles; Con, control. 
We found that Cis alone or rGO-AgNPs alone resulted in an immediate elevation of cellular ROS levels, while Cis plus rGO-AgNP treatment showed a more pronounced effect. We found that rGO-AgNPs sharply elevated the level of ROS with Cis (Figure 9A). Previous research suggests that platinum-based chemotherapeutic agents can elevate the level of ROS in bladder cancer cells, which could enhance therapeutic strategy via increasing cytotoxicity by manipulating the oxidation-reduction status of cancer cells. ${ }^{54}$ These data indicated that the synergistic effect of rGO-AgNPs on enhancement of Cis-induced cytotoxicity was related to the generation of ROS in cells.

LDH is another cytotoxicity marker, and can be determined by measuring the release of LDH into the media. ${ }^{19}$ AgNPs, GO, and rGO can induce the leakage of LDH into the media and significantly induce cytotoxicity in various types of cancer cell lines. ${ }^{22,24,32}$ Next, we examined the effect of Cis,
rGO-AgNPs, or a combination of both in LDH-induced cell toxicity. To study LDH leakage, we measured the LDH level after exposing HeLa cells to Cis, rGO-AgNPs, or a combination of both for 24 hours. We found that Cis alone or rGOAgNPs alone resulted in increased LDH leakage; indeed, the combination of both had a much stronger cytotoxic effect. Therefore, we found that rGO-AgNPs can sharply elevate the level of LDH with Cis (Figure 9B).

Lipids are susceptible targets of oxidation. ${ }^{55,56} \mathrm{MDA}$ is a well-studied marker of lipid peroxidation. ${ }^{13,55,56} \mathrm{We}$ investigated the combined effect of $\mathrm{Cis}$ and $\mathrm{rGO}-\mathrm{AgNPs}$ on oxidative stress by measuring MDA levels. MDA levels in control, Cis-treated, rGO-AgNP-treated, and Cis plus rGOAgNP-treated cells were $1 \mathrm{nmol} / \mathrm{mg}, 5 \mathrm{nmol} / \mathrm{mg}, 6 \mathrm{nmol} / \mathrm{mg}$, and $9 \mathrm{nmol} / \mathrm{mg}$ of protein, respectively. MDA levels were significantly higher in Cis, rGO-AgNPs, and combined treatment than control. Interestingly, we found that the
A

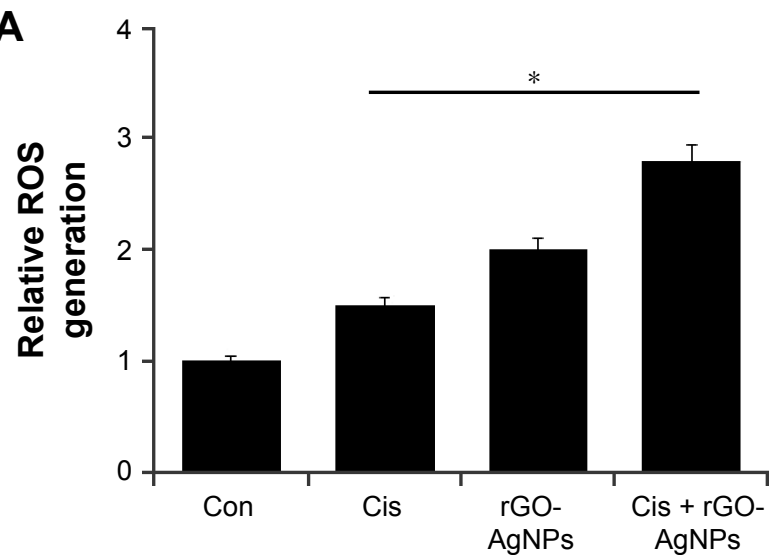

C

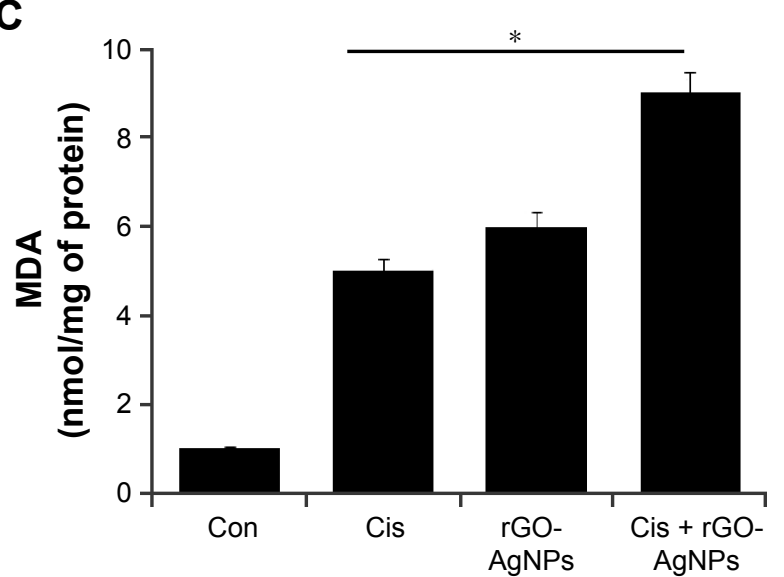

B

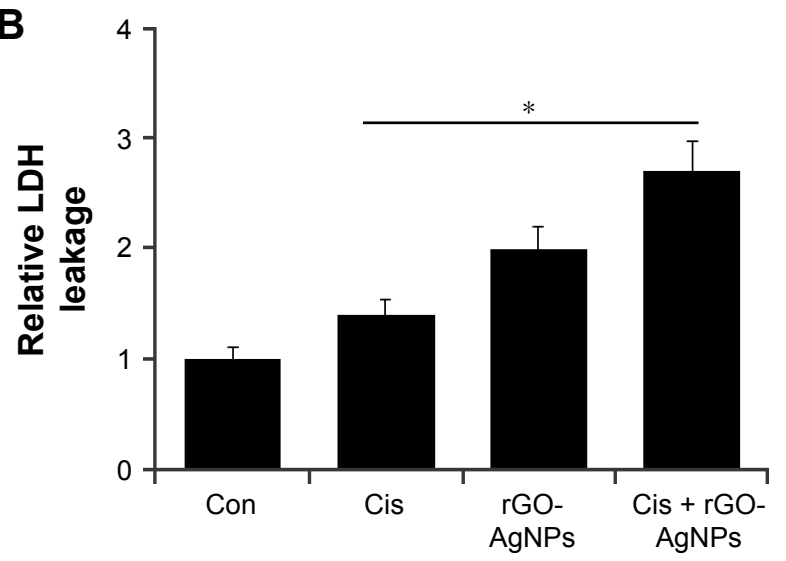

D

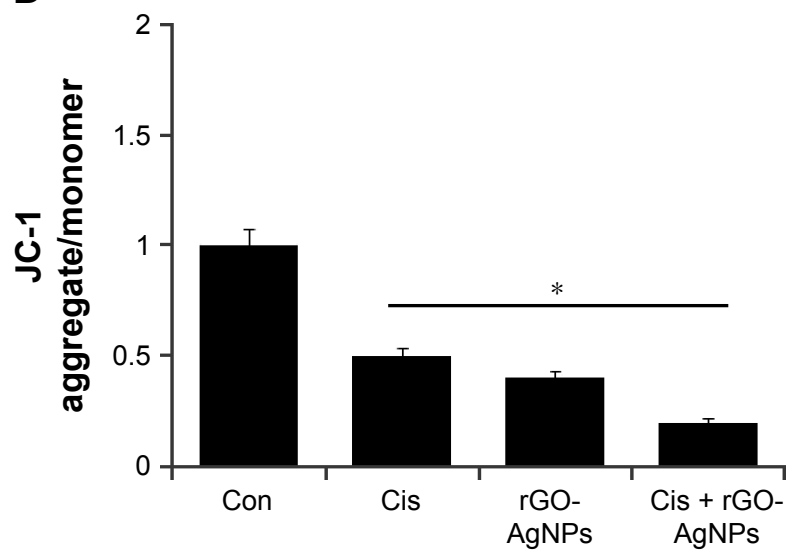

Figure 9 The effect of Cis or rGO-AgNPs alone or the combinatorial effect of Cis plus rGO-AgNPs on cell cytotoxicity in HeLa cells.

Notes: HeLa cells were incubated with Cis $(5 \mu \mathrm{M})$ or $\mathrm{rGO}$-AgNPs $(\mathrm{I} \mu \mathrm{g} / \mathrm{mL})$ or a combination of Cis plus rGO-AgNPs for 24 hours. (A) ROS were measured, as relative fluorescence of 2',7'-dichlorofluorescein, with spectrofluorometry. (B) LDH activity was measured at $490 \mathrm{~nm}$, using an LDH-cytotoxicity kit. (C) The concentration of MDA was measured and expressed as nanomoles per milligram of protein. (D) MMP (ratio of JC-I aggregate to monomer) was determined using JC-I cationic dye after treatment. Results are expressed as mean \pm standard deviation of three independent experiments. Treated groups showed statistically significant differences from the Con group, as determined by Student's $t$-test $(* P<0.05)$.

Abbreviations: Cis, cisplatin; rGO, reduced graphene oxide; NPs, nanoparticles; ROS, reactive oxygen species; MDA, malondialdehyde; MMP, mitochondrial membrane potential; Con, control. 
combined treatment showed significant elevation of MDA levels (Figure 9C). SW620 cells treated with salinomycin show an abundance of lipid peroxides with increased LDH release and MDA levels. ${ }^{57}$

Mitochondria play an important role in inducing and triggering apoptosis. ${ }^{58,59}$ To determine the combined effect of $\mathrm{Cis}$ and $\mathrm{rGO}-\mathrm{AgNPs}$ in mitochondrial function and their role in inducing cell death, the JC-1 assay was performed. We measured the loss of MMP in cells treated with Cis, rGOAgNPs, or a combination thereof. As shown in Figure 9D, cells treated with $\mathrm{Cis}(5 \mu \mathrm{M})$ and rGO-AgNPs $(1 \mu \mathrm{g} / \mathrm{mL})$ showed an imbalance ratio between green fluorescence and red fluorescence; interestingly, the combination of both $\mathrm{Cis}$ and rGO-AgNPs exhibited remarkable difference from the control as well as the single treatments. The results from this study suggest that the red-green fluorescence intensity (aggregate:monomer) ratio was decreased to 50\%, 40\%, and $80 \%$ in Cis-treated, rGO-AgNP-treated, and Cis plus rGOAgNP-treated cells, respectively (Figure 9D). Cells treated with Cis, rGO-AgNPs, or a combination of both clearly showed a lower JC-1 red-green fluorescence-intensity ratio, indicating a loss of mitochondrial membrane integrity. These data suggest that $\mathrm{Cis}$ or rGO-AgNPs alone were able to induce a significant increase in the proportion of cells exhibiting a loss of MMP, and this effect was potentially enhanced by the combination of Cis with rGO-AgNPs. Studies have reported that AgNPs can induce mitochondria-mediated apoptosis by loss of MMP in A549 human lung-carcinoma cells and also in combination with salinomycin in human ovarian cancer cells. ${ }^{13,25}$ Similarly, apoptosis-inducing agents can trigger uncoupling of electron transport from ATP production and lead to MMP loss and ROS production. ${ }^{60,61} \mathrm{Cis}$ induces remarkable mitochondrial changes in HeLa cells. ${ }^{62}$ Altogether, the combination of Cis and rGO-AgNPs causes loss of MMP and eventually leads to apoptosis.

\section{Combination effect of Cis and rGO- AgNPs on antioxidant molecules}

Antioxidants are able to protect cells from Cis-induced cytotoxicity or NP-induced cytotoxicity. ${ }^{31,63,64}$ If Cis or rGO-AgNPs induce cytotoxicity by generation of ROS, the level of antioxidants might be compromised. Therefore, we investigated the level of such antioxidants as GSH, the ratio of GSH:GSSG, SOD, and CAT. As we expected, levels of GSH, GSH:GSSG ratio, SOD, and CAT decreased compared to control (Figure 10). The level of GSH is critical in controlling various cellular functions, including cell differentiation, proliferation, and apoptosis. ${ }^{65}$ An imbalance of the oxidation-reduction system causes etiology and progression of many human diseases, including cancer. ${ }^{65}$ The antioxidant defense system involving GSH, GSSG, SOD, and CAT controls ROS levels and is important to regulate various cellular functions. These results suggest that $\mathrm{Cis}$ and $\mathrm{rGO}-\mathrm{AgNPs}$ lead to a condition of oxidative stress in cells, which may arise due to the imbalance of oxidant and antioxidant levels in cells ${ }^{56}$ Altogether, the data from this experiment suggest that the combination of Cis and rGO-AgNPs induces significantly lower levels of antioxidant molecules in the system, which could be the reason for the cause of cytotoxicity.

\section{Combination of Cis and rGO-AgNPs enhances upregulation of proapoptotic genes}

P53 is known to play a dual role in stress response by regulating a number of genes, including $P 21$, into cell-cycle arrest. ${ }^{66,67}$ It is involved in the activation of apoptosis in the case of DNA damage induced by salinomycin and AgNPs, ${ }^{13,25}$ and regulates many genes that are critical for determining the cellular response to DNA damage. It is known to activate the transcription of death agonist $B A X$, but to repress the expression of BCL2. ${ }^{68}$ Given the roles of several pro- and antiapoptotic genes in cell death and survival, we examined the expression of the P53, P21, BAX,BAK, BCL2, BCL2L1, $C A S P 3$, and $C A S P 9$ genes in HeLa cells. Furthermore, to investigate the effect of their expression in response to Cis, rGO-AgNPs, or a combination of both, we attempted to understand the molecular events contributing to the apoptosis. Cells were treated with Cis $(5 \mu \mathrm{M})$, rGO-AgNPs $(1 \mu \mathrm{g} / \mathrm{mL})$, or Cis plus rGO-AgNPs, and mRNA expression was determined by RT-PCR. Cells treated with Cis, rGOAgNPs, or a combination of both showed upregulation of P53, BAX, BAK, CASP3, and CASP9, whereas BCL2 and $B C L 2 L 1$ showed decreased expression. The combination treatment showed significant upregulation of all tested apoptotic genes, including $P 53, P 21, B A X, B A K, C A S P 3$, and $C A S P 9$, and downregulation of antiapoptotic genes, such as BCL2 and BCL2L1 (Figure 11). In Cis-treated or rGO-AgNPtreated HeLa cells, we found 0.5- to twofold upregulation of proapoptotic genes, whereas the combination of $\mathrm{Cis}$ and rGO-AgNPs showed up to threefold. Figure 11 shows that Cis or rGO-AgNPs were able markedly to downregulate the expression of the BCL2 and BCL2L1 genes in HeLa compared with untreated cells $(P<0.05)$. In the group treated with a combination treatment of Cis plus rGO-AgNPs, a marked decrease in BCL2 and BCL2L1 was detected compared with untreated cells $(P<0.05)$. In general, we observed in HeLa 

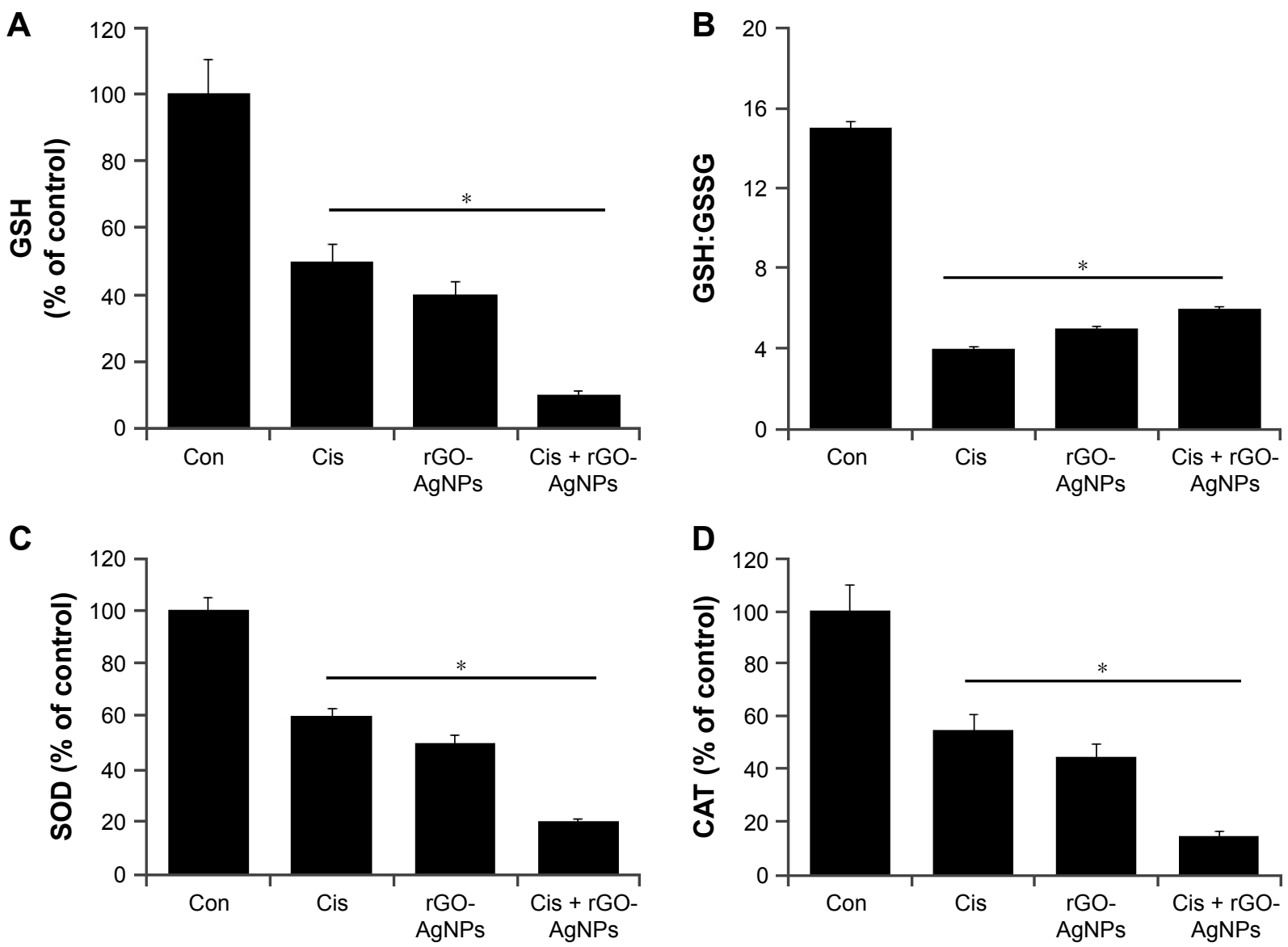

Figure 10 Effect of Cis or rGO-AgNPs alone or the combinatorial effect of Cis plus rGO-AgNPs on antioxidant markers in HeLa cells.

Notes: Cells were treated with Cis $(5 \mu \mathrm{M})$, rGO-AgNPs $(I \mu \mathrm{g} / \mathrm{mL})$, or both Cis $(5 \mu \mathrm{M})$ and $\mathrm{rGO}-\mathrm{AgNPs}(\mathrm{I} \mu \mathrm{g} / \mathrm{mL})$ for 24 hours. After incubation, the cells were harvested and washed twice with an ice-cold phosphate-buffered saline solution. The cells were collected and disrupted by ultrasonication for 5 minutes on ice. (A) GSH concentration is expressed as mg/g of protein. (B) Ratio of GSH:GSSG. (C) Specific activity of SOD is expressed as units per milligram of protein. (D) Specific activity of CAT is expressed as units per milligram of protein. Results are expressed as mean \pm standard deviation of three independent experiments. There was a significant difference in treated cells compared to untreated cells with Student's $t$-test $(* P<0.05)$.

Abbreviations: Cis, cisplatin; rGO, reduced graphene oxide; NPs, nanoparticles; GSH, glutathione; GSSG, glutathione disulfide; Con, control.

cells an upregulation of $C A S P 3$ and $C A S P 9$, which are implicated in the mitochondrial pathway of apoptosis. ${ }^{69}$ Our results accorded well with HeLa cells treated with pentoxifylline and Cis. ${ }^{70}$ Collectively, our work demonstrated that the combination of $\mathrm{Cis}$ and $\mathrm{rGO}-\mathrm{AgNPs}$ promoted apoptosis in HeLa cells, as confirmed by the overexpression of P53, P21, $B A X, B A K, C A S P 3$, and CASP9.

\section{Combination of $\mathrm{Cis}$ and rGO-AgNPs enhances DNA fragmentation}

Apoptosis or programmed cell death is a fundamental, complex biological process involving elimination of defective and dangerous cells and disease. ${ }^{13,71}$ Apoptosis can be confirmed by abnormal reduction in the size of cells and DNA fragmentation, ${ }^{13}$ and $\mathrm{p} 53$ is involved in the activation of apoptosis induced by DNA-damaging anticancer agents. ${ }^{72-74}$ Previously, we have shown biologically synthesized AgNPs, $\mathrm{GO}$, resveratrol-reduced $\mathrm{GO}$, and plant extract-mediated
rGO-AgNPs induce DNA fragmentation in various cancer cell lines, such as human breast cancer cells and ovarian cancer cells. $^{22,23,25}$ To examine DNA fragmentation, cells were treated with Cis $(5 \mu \mathrm{M})$, rGO-AgNPs $(1 \mu \mathrm{g} / \mathrm{mL})$, or Cis plus rGO-AgNPs for 24 hours, and apoptotic signals were determined using TUNEL assay. Cis or rGO-AgNPs alone induced apoptosis significantly compared to untreated cells. Interestingly, the proapoptotic effects of $\mathrm{Cis}$ were potentiated when $5 \mu \mathrm{M}$ Cis and $1 \mu \mathrm{M}$ rGO-AgNPs were concomitantly administered for 24 hours. The combination of $\mathrm{Cis}$ and $\mathrm{rGO}-\mathrm{AgNPs}$ significantly enhanced apoptosis over that of a single treatment (Figure 12). Actually, the number of apoptotic signals was significantly improved in combined treatment compared to single treatment with either Cis or rGO-AgNPs (Figure 12). Similarly, melatonin potentiates Cis-induced oxidative stress and DNA fragmentation in HeLa cells. ${ }^{75}$ Recently, our findings suggested that rGO-AgNPs are a powerful prooxidant and detrimental in human ovarian 


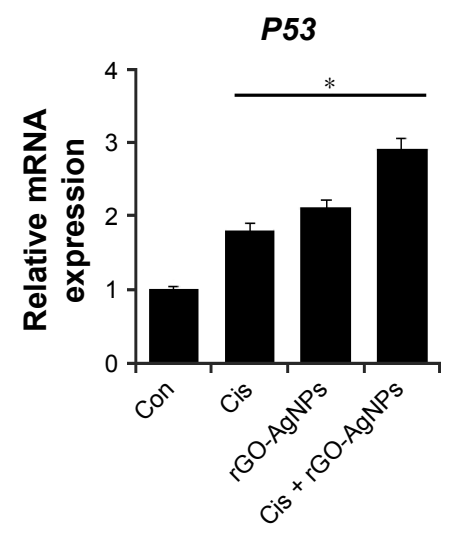

BCL2

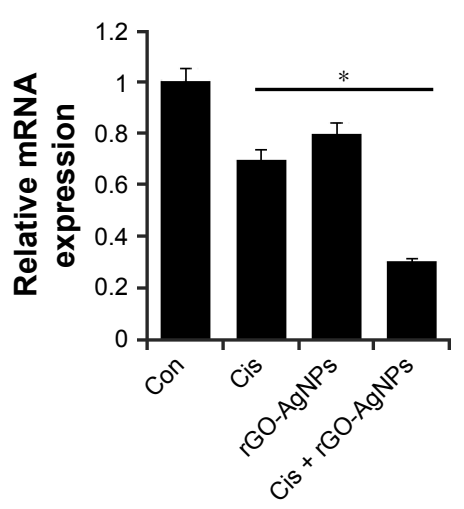

P21

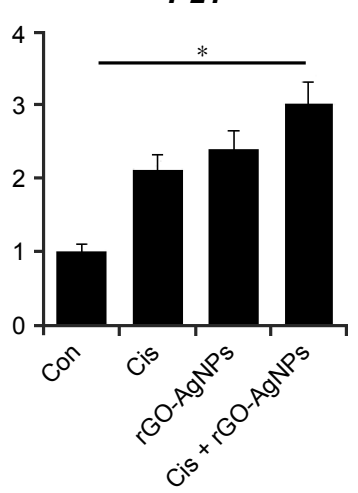

$B C L-X L$

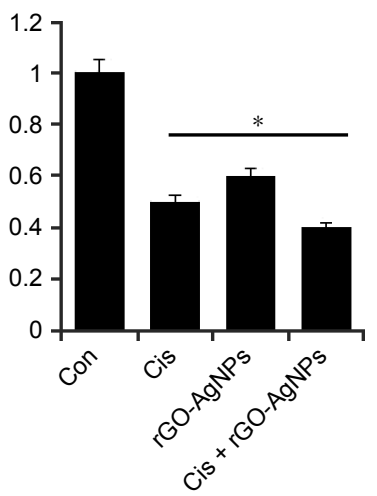

$B A X$

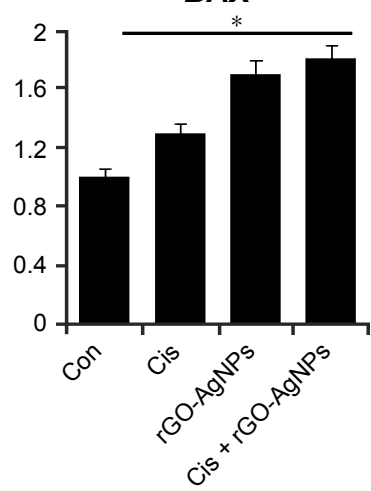

CASP3

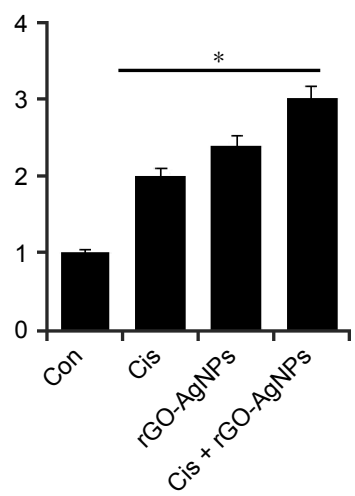

BAK

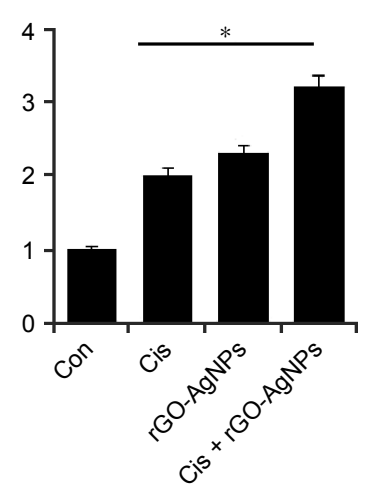

CASP9

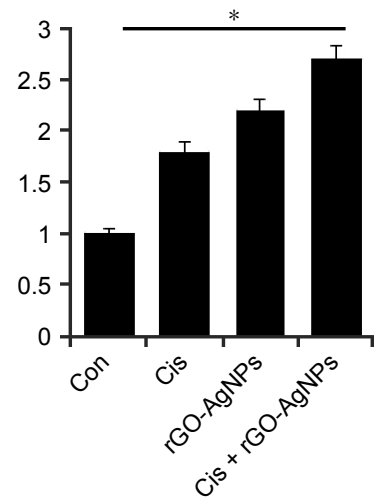

Figure I I Combination of Cis and rGO-AgNPs increased the expression of proapoptotic genes and decreased the expression of antiapoptotic genes. Notes: The cells were treated with Cis $(5 \mu \mathrm{M})$, rGO-AgNPs $(I \mu \mathrm{g} / \mathrm{mL})$, or both Cis $(5 \mu \mathrm{M})$ and rGO-AgNPs $(I \mu g / \mathrm{mL})$ for 24 hours. Relative messenger RNA (mRNA) expression of apoptotic and antiapoptotic genes was analyzed by quantitative reverse-transcription polymerase chain reaction in HeLa cells treated for 24 hours. Results are expressed as mean \pm standard deviation of three independent experiments. The treated groups showed statistically significant differences from the Con group by Student's t-test $(* P<0.05)$

Abbreviations: Cis, cisplatin; rGO, reduced graphene oxide; NPs, nanoparticles; Con, control.

cells, due to overproduction of ROS..$^{21}$ In the current study, we have provided evidence that rGO-AgNPs stimulate intracellular ROS overproduction when combined with Cis, and hence oxidative stress, in HeLa cells, as ascertained by increments in caspase 3 and caspase 9 leading to cell death.

\section{Cis and rGO-AgNPs synergistically induce autophagy}

The induction of autophagy is to maintain cell survival under various cellular stresses, and its continuous activation can lead to caspase-independent autophagic cell death. ${ }^{76,77}$ Chemotherapy-induced inhibitory effects on cell viability and cell proliferation usually leads to the demise of cancer cells, which can be mediated by either apoptotic or autophagic pathways. Previous studies have indicated that autophagy can act as both an inhibitor and enabler of programmed cell death. ${ }^{77,78}$ The role of autophagy in cancer cells depends highly on cell types and inducers. To investigate whether the synergistic effect of cell death caused by cotreatment induces autophagic cell death, we examined the expression of various autophagy genes such as $A T G 3, A T G 5, A T G 6$, $A T G 7, A T G 10, A T G 12$, and $A T G 17$. Cells were treated with Cis $(5 \mu \mathrm{M}), \mathrm{rGO}-\mathrm{AgNPs}(1 \mu \mathrm{g} / \mathrm{mL})$, or Cis plus rGO-AgNPs for 24 hours, and then mRNA-expression levels were estimated by RT-PCR. Following the combination treatment, the relative expression levels of various autophagy genes were upregulated up to threefold over the control group (Figure 13). Bao et al demonstrated that Cis induced the formation of autophagosomes and upregulated the expression of the autophagy-related genes ATG3, ATG6, and ATG12 in the human ovarian carcinoma cell line A2780 and its Cis-resistant variant - A2780cp. ${ }^{79}$ Sublethal concentrations of DNA-damaging drugs, such as etoposide and Cis, induce the expression of Atg5, which is both necessary and sufficient for the subsequent induction of mitotic catastrophe..$^{80}$ The molecular mechanisms of autophagosome formation are conserved in evolution and depend upon several autophagyrelated proteins. In particular, Atg5 is able to be conjugated with Atg12 to generate an E3 ubiquitin ligase-like enzyme required for autophagy. ${ }^{81}$ In agreement with earlier reports, 


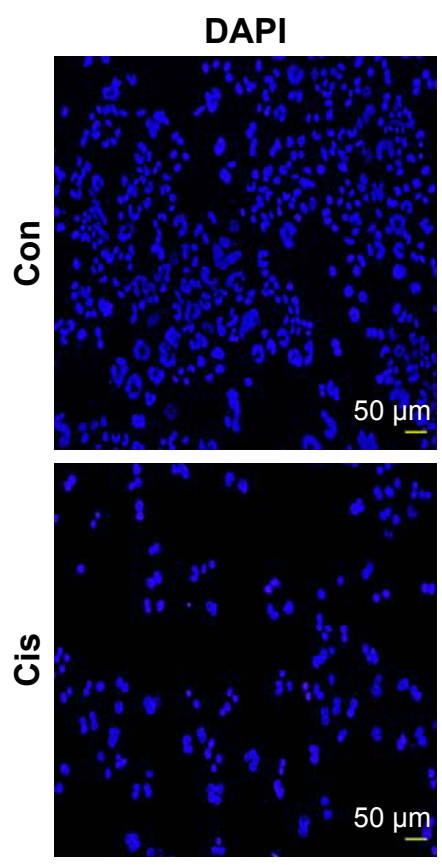

DAPI
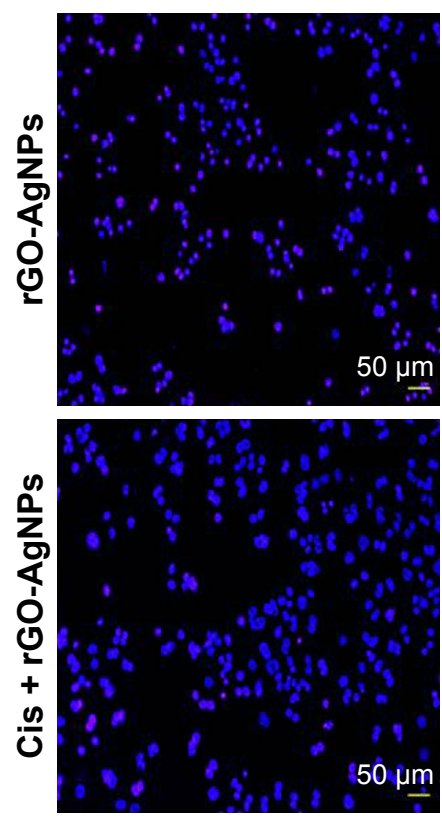

TUNEL
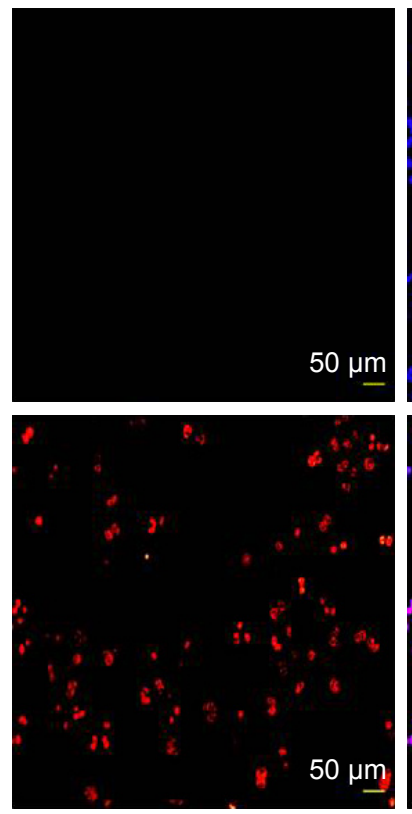

TUNEL
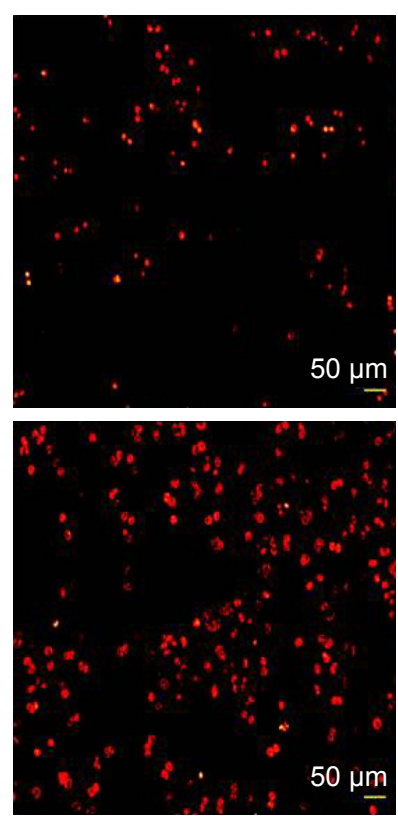

Merge

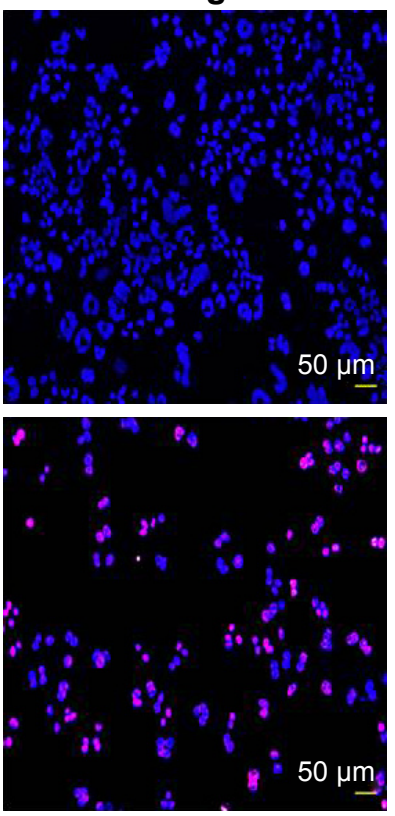

Merge
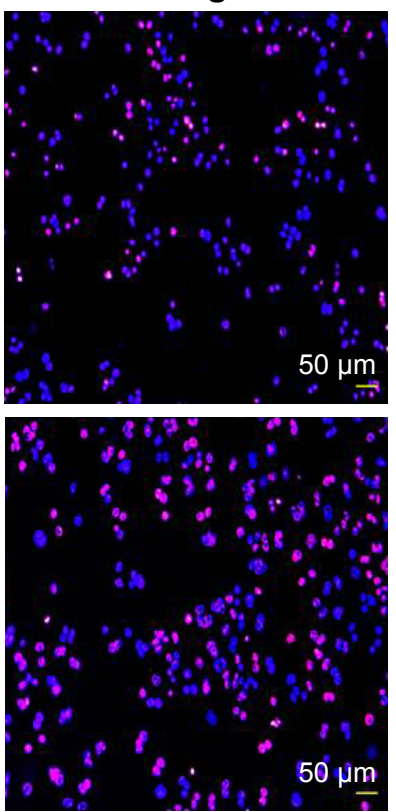

Figure 12 Combination of Cis and rGO-AgNPs enhanced apoptosis.

Notes: Cells were treated with Cis $(5 \mu \mathrm{M})$, rGO-AgNPs $(\mathrm{I} \mu \mathrm{g} / \mathrm{mL})$, or both Cis $(5 \mu \mathrm{M})$ and rGO-AgNPs $(\mathrm{I} \mu \mathrm{g} / \mathrm{mL})$ for 24 hours. Apoptosis was assessed with a TUNEL assay; the nuclei were counterstained with DAPI. Representative images show apoptotic (fragmented) DNA (red staining) and corresponding cell nuclei (blue staining). Abbreviations: Cis, cisplatin; rGO, reduced graphene oxide; NPs, nanoparticles; Con, control.

this study also supported the role of $A T G 5$ and $A T G 12$ in the formation of autophagosomes, based on the five and sevenfold overexpression of these two genes, respectively, compared with other $A T G$ genes. Maskey et $\mathrm{al}^{80}$ further demonstrated that elevated levels of $A T G 5$ are necessary for both drug-induced autophagy and mitotic catastrophe. Recent research has suggested that $\mathrm{C}$ is increases expression of the autophagy-related $A T G 7$ gene. ${ }^{80-82}$ Exposure of squamous cell carcinoma to $\mathrm{Cis}$ leads to modulation of members of the autophagic pathway, such as $A T G 1 / U L K 1, A T G 3$, ATG4A, ATG5, ATG6/BECN1, ATG7, ATG9A, and ATG10, by direct $\mathrm{p}-\Delta \mathrm{Np} 63 \alpha$-dependent transcriptional regulation. ${ }^{83}$ Altogether, our data suggest that Cis, rGO-AgNPs, or a combination of both can modulate the expression of autophagy-related genes and eventually induce apoptosis in HeLa cells. 

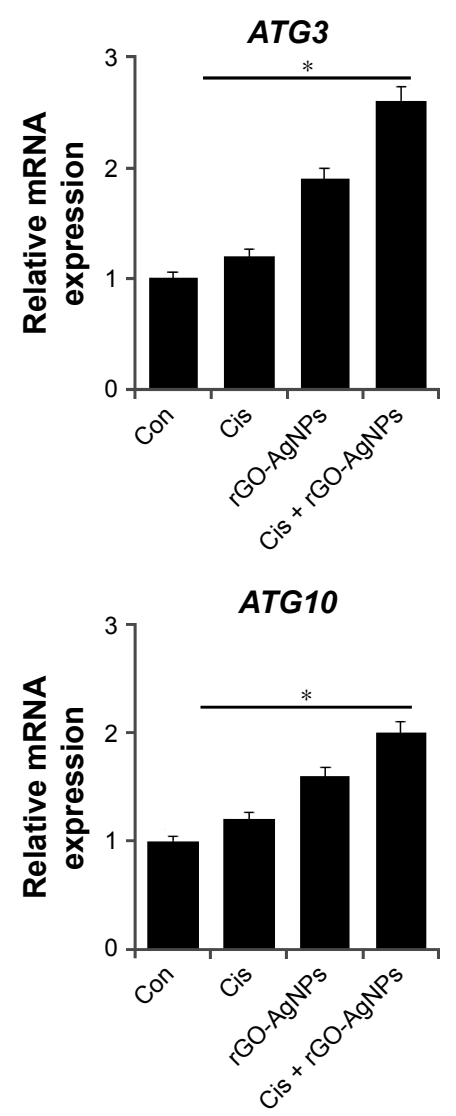
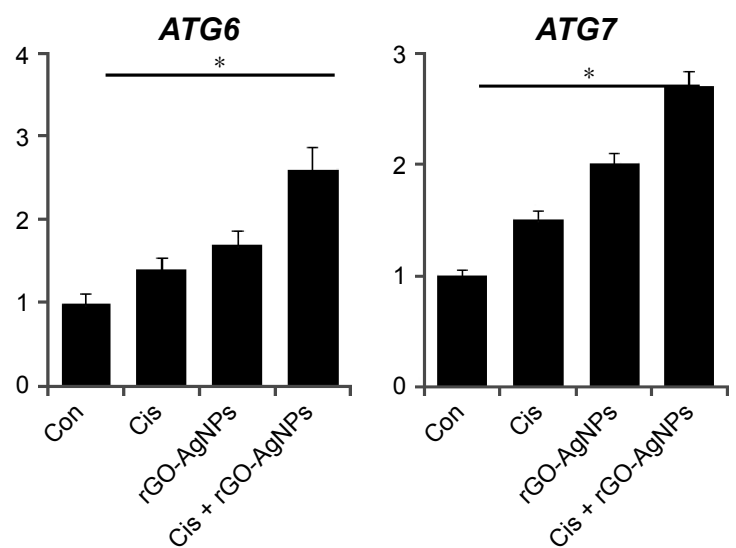

ATG17
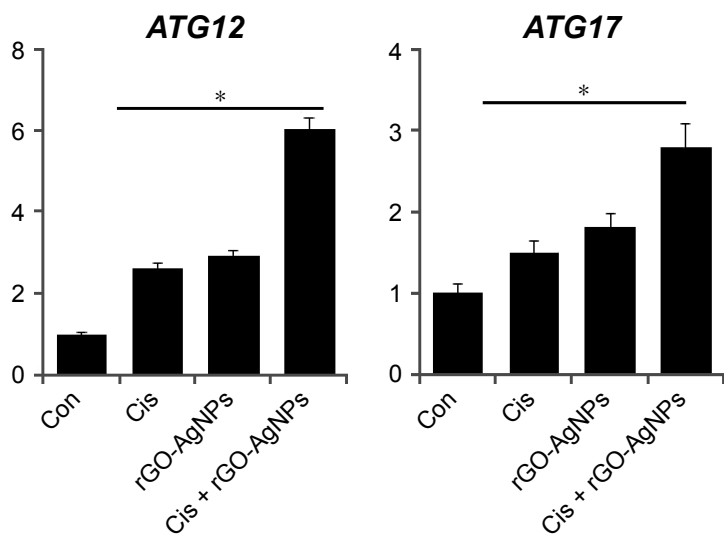

Figure 13 Effect of Cis and rGO-AgNPs on expression of autophagy-regulated genes in HeLa cells.

Notes: Cells were treated with Cis $(5 \mu \mathrm{M})$, rGO-AgNPs $(\mathrm{I} \mu \mathrm{g} / \mathrm{mL})$, or both Cis $(5 \mu \mathrm{M})$ and rGO-AgNPs (I $\mu \mathrm{g} / \mathrm{mL})$ for 24 hours. Relative messenger RNA (mRNA) expression of autophagy genes was analyzed by quantitative reverse-transcription polymerase chain reaction in HeLa cells treated for 24 hours. Results are expressed as mean \pm standard deviation of three independent experiments. The treated groups showed statistically significant differences from the Con group by Student's $t$-test $(* P<0.05)$.

Abbreviations: Cis, cisplatin; rGO, reduced graphene oxide; NPs, nanoparticles; Con, control.

\section{Combination of $\mathrm{Cis}$ and rGO-AgNPs induces accumulation of \\ autophagolysosomes}

To confirm further that combined therapy induces autophagy in HeLa cells, we used TEM to measure autophagosome formation. TEM analysis confirmed that the structures of autophagic vacuoles were largely detected in the combination-treatment group compared to its monotherapy controls (Figure 14). These results suggest that the cell death caused by the combined treatment with Cis and rGOAgNPs was remarkable. Further, the combined treatment induced accumulation of autophagolysosomes, formed along with lysosomes, phagosomes, and autophagosomes. Recently, Han et al observed that the AgNPs induced accumulation of autophagosomes and autolysosomes in human lung carcinoma cells and combination of salinomycin and AgNPs enhanced the expression of various autophagy genes and accumulation of autophagosomes, lysosomes, and autophagolysosomes in human ovarian cancer cells. ${ }^{13,84}$
Once autophagosomes are formed, they can merge with lysosomes to form autolysosomes, whose contents are degraded by lysosomal hydrolases. ${ }^{81}$

Although autophagy seems to protect cells against cell death under oxidative stress, extended autophagy can induce cell death in several cases, such as precancerous cells. ${ }^{13,85-88}$ Recent studies suggest a potential link between ROS regulation and autophagic processes, because agents capable of inducing ROS formation play a crucial role in the induction of autophagy in embryonic kidney HEK293 cells, human fibroblast HT1080 cells, and human lung cancer cells. ${ }^{84,89,90}$ For instance, platinum-based therapy and epigallocatechin gallate-mediated cell death may also depend on the generation of ROS either directly or indirectly. ${ }^{91,92}$ A recent study suggested that Cis induces autophagy in HeLa cells via upregulating the formation of autophagic vesicles, promoting the conversion of LCI to LCII and increasing the expression of the autophagy-related $A T G 7$ gene. ${ }^{82}$ Our findings provide evidence that the autophagy induced by $\mathrm{Cis}$ 

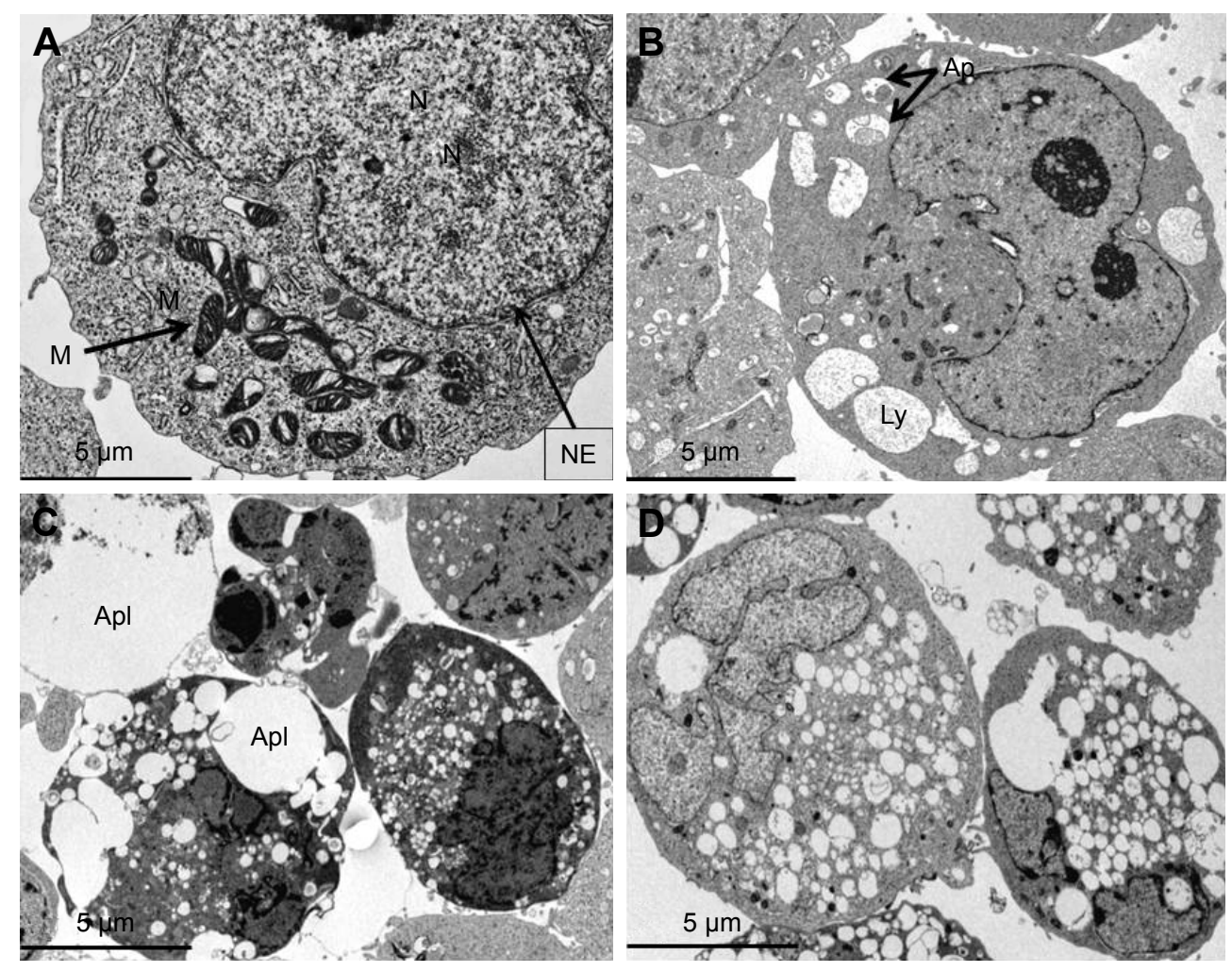

Figure 14 The combination of $\mathrm{Cis}$ and rGO-AgNPs induced accumulation of autophagolysosomes.

Notes: Cells were treated with (A) control (B) Cis $(5 \mu \mathrm{M}),(\mathbf{C})$ rGO-AgNPs (I $\mu \mathrm{g} / \mathrm{mL})$, or (D) both Cis $(5 \mu \mathrm{M})$ and rGO-AgNPs (I $\mu \mathrm{g} / \mathrm{mL})$ for 24 hours and processed for electron microscopy. Cis $(5 \mu \mathrm{M})$-, rGO-AgNP $(I \mu g / \mathrm{mL})$-, or both Cis $(5 \mu \mathrm{M})$ - and rGO-AgNP $(\mathrm{I} \mu g / \mathrm{mL})$-treated cells showed an increased number of autophagolysosomes formed, along with lysosomes, phagosomes, and autophagosomes.

Abbreviations: Cis, cisplatin; rGO, reduced graphene oxide; NPs, nanoparticles; M, mitochondrion; N, nucleus; NE, nuclear envelope; Ap, autophagosome; Apl, autophagolysosome; Ly, lysosome.

plus rGO-AgNPs was significant over that induced by Cis or rGO-AgNPs. Overall, the combination of Cis plus rGOAgNPs enhanced cell death via apoptosis and autophagy by increasing the expression levels of $P 53, P 21, B A X$, and $B A K$, activation of caspases, and enhanced expression of ATG3, ATG5, ATG6, ATG7, ATG12, and ATG17, which are responsible for the formation of autophagolysosomes. Our studies are more relevant with newly formulated engineered biodegradable polymer NPs containing combinations of Cis and polymer NPs, which are highly efficient in delivery with precise doses of various chemotherapeutic agents for cancer. ${ }^{93-95}$ Collectively, our findings suggest that combining chemotherapeutic agents, such as Cis, with rGO-AgNPs could potentiate the cytotoxicity of Cis in HeLa cells through apoptosis- and autophagy-related pathways.

\section{Conclusion}

Cis is one of the most active anticancer agents utilized for the treatment of a variety of cancers, and Cis-based therapy produces a statistically significant clinical improvement in survival. Similarly, AgNPs and graphene are relatively well-known anticancer agents. To optimize the synergistic efficacy of Cis, we propose a combination therapy involving biologically synthesized rGO-AgNPs with Cis that could distinctly enhance cytotoxic effects in HeLa cells. Therefore, this study was designed to investigate the combined effect of two different potentially cytotoxic and efficient molecules in HeLa cells. Our findings substantiated that rGO-AgNPs strongly enhanced the sensitivity of Cis in HeLa cells. This fact seems to be linked to the ability of the Cis and rGOAgNPs to enter ROS-mediated mitochondria-dependent apoptosis, which in turn resulted in increased proapoptotic gene expression, including P53, P21, BAX, BAK, CASP3, and $C A S P 9$, and decreased expression of antiapoptotic genes, including $B C L 2$ and $B C L 2 L 1$, and eventually increased DNA fragmentation. Therefore, findings on the combination effect of Cis and rGO-AgNPs in HeLa cells seem to be consistent, suggesting that rGO-AgNPs could be potentially applied as adjuvant agents to improve the therapeutic effect of chemotherapy, particularly of platinum-based therapy. It would be thus interesting to perform further mechanistic studies, including cell-cycle redistribution, induction of apoptosis, 
and downregulation of survival signals, to corroborate the results obtained in the present research.

\section{Acknowledgments}

This paper was supported by the KU Research Professor Program of Konkuk University. This study was supported by the Priority Academic Program Development of Jiangsu Higher Education Institutions (PAPD), Intergovernmental Science and Technology CooperaProject (S2016G6252), and China Postdoctoral Science Foundation (2015M571827/1402001C).

\section{Disclosure}

The authors report no conflicts of interest in this work.

\section{References}

1. International Agency for Research on Cancer. Cervical cancer: estimated incidence, mortality and prevalence worldwide in 2012. Available from: http://globocan.iarc.fr/old/FactSheets/cancers/cervix-new.asp. Accessed August 1, 2016.

2. American Cancer Society. Chemotherapy for cervical cancer. 2016. Available from: http://www.cancer.org/cancer/cervicalcancer/detailedguide/ cervical-cancer-treating-chemotherapy. Accessed August 1, 2016.

3. Jemal A, Bray F, Center MM, Ferlay J, Ward E, Forman D. Global cancer statistics. CA Cancer J Clin. 2011;61(2):69-90.

4. Ferlay J, Soerjomataram I, Dikshit R, et al. Cancer incidence and mortality worldwide: Sources, methods and major patterns in GLOBOCAN 2012. Int J Cancer. 2015;136(5):E359-E386.

5. Anton M, Horký M, Kuchtícková S, Vojtěsek B, Bláha O. Immunohistochemical detection of acetylation and phosphorylation of histone H3 in cervical smears. Ceska Gynekol. 2004;69(1):3-6.

6. Dueñas-González A, Lizano M, Candelaria M, Cetina L, Arce C, Cervera E. Epigenetics of cervical cancer: an overview and therapeutic perspectives. Mol Cancer. 2005;4:38.

7. American Cancer Society. What are the key statistics about cervical cancer? 2016. Available from: http://www.cancer.org/cancer/ cervicalcancer/detailedguide/cervical-cancer-key-statistics. Accessed January 6, 2017.

8. Soonthornthum T, Arias-Pulido H, Joste N, et al. Epidermal growth factor receptor as a biomarker for cervical cancer. Ann Oncol. 2011; 22(10):2166-2178.

9. Zhang P, Xi M, Zhao L, et al. Clinical efficacy and failure pattern in patients with cervical esophageal cancer treated with definitive chemoradiotherapy. Radiother Oncol. 2015;116(2):257-261.

10. Asano T, Hirohashi Y, Torigoe T, et al. Brother of the regulator of the imprinted site (BORIS) variant subfamily 6 is involved in cervical cancer stemness and can be a target of immunotherapy. Oncotarget. 2016; 7(10):11223-11237.

11. Blanco E, Hsiao A, Ruiz-Esparza GU, Landry MG, Meric-Bernstam F, Ferrari M. Molecular-targeted nanotherapies in cancer: enabling treatment specificity. Mol Oncol. 2011;5(6):492-503.

12. Li F, Zhao C, Wang L. Molecular-targeted agents combination therapy for cancer: developments and potentials. Int J Cancer. 2014;134(6): $1257-1269$

13. Zhang XF, Gurunathan S. Combination of salinomycin and silver nanoparticles enhances apoptosis and autophagy in human ovarian cancer cells: an effective anticancer therapy. Int J Nanomedicine. 2016;11: 3655-3675.

14. Harris TJ, von Maltzahn G, Bhatia SN. Multifunctional nanoparticles for cancer therapy. In: Amiji MM, editor. Nanotechnology for Cancer Therapy. Boca Raton (FL): CRC Press; 2006:59-75.
15. Xiao B, Ma L, Merlin D. Nanoparticle-mediated co-delivery of chemotherapeutic agent and siRNA for combination cancer therapy. Expert Opin Drug Deliv. 2017;14(1):65-73.

16. Duan X, He C, Kron SJ, Lin W. Nanoparticle formulations of cisplatin for cancer therapy. Wiley Interdiscip Rev Nanomed Nanobiotechnol. 2016;8(5):776-791.

17. Melanie K, Heike Z, Sibylle BS, et al. Characterization of iron oxide nanoparticles adsorbed with cisplatin for biomedical applications. Phys Med Biol. 2009;54(17):5109-5121.

18. Comenge J, Sotelo C, Romero F, et al. Detoxifying antitumoral drugs via nanoconjugation: the case of gold nanoparticles and cisplatin. PloS One. 2012;7(10):e47562.

19. Zhang XF, Yan Q, Shen W, Gurunathan S. Trichostatin A enhances the apoptotic potential of palladium nanoparticles in human cervical cancer cells. Int J Mol Sci. 2016;17(8):E1354.

20. Geim AK, Novoselov KS. The rise of graphene. Nat Mater. 2007;6(3): 183-191.

21. Gurunathan S, Han JW, Park JH, et al. Reduced graphene oxidesilver nanoparticle nanocomposite: a potential anticancer nanotherapy. Int J Nanomedicine. 2015;10:6257-6276.

22. Gurunathan S, Han JW, Eppakayala V, Kim JH. Green synthesis of graphene and its cytotoxic effects in human breast cancer cells. Int J Nanomedicine. 2013;8:1015-1027.

23. Gurunathan S, Han JW, Kim ES, Park JH, Kim JH. Reduction of graphene oxide by resveratrol: a novel and simple biological method for the synthesis of an effective anticancer nanotherapeutic molecule. Int J Nanomedicine. 2015;10:2951-2969.

24. Gurunathan S, Han JW, Eppakayala V, Jeyaraj M, Kim JH. Cytotoxicity of biologically synthesized silver nanoparticles in MDA-MB-231 human breast cancer cells. Biomed Res Int. 2013;2013:535796.

25. Gurunathan S, Jeong JK, Han JW, Zhang XF, Park JH, Kim JH. Multidimensional effects of biologically synthesized silver nanoparticles in Helicobacter pylori, Helicobacter felis, and human lung (L132) and lung carcinoma A549 cells. Nanoscale Res Lett. 2015;10:1-17.

26. Yu L, Zhang Y, Zhang B, Liu J. Enhanced antibacterial activity of silver nanoparticles/halloysite nanotubes/graphene nanocomposites with sandwich-like structure. Sci Rep. 2014;4:4551.

27. Yang YK, He CE, He WJ, et al. Reduction of silver nanoparticles onto graphene oxide nanosheets with $\mathrm{N}, \mathrm{N}$-dimethylformamide and SERS activities of GO/Ag composites. J Nanopart Res. 2011;13(10): 5571-5581.

28. Zhang Z, Xu FG, Yang WS, et al. A facile one-pot method to high-quality Ag-graphene composite nanosheets for efficient surface-enhanced Raman scattering. Chem Commun. 2011;47(22):6440-6442.

29. Chen XM, Su BY, Wu GH, et al. Platinum nanoflowers supported on graphene oxide nanosheets: their green synthesis, growth mechanism, and advanced electrocatalytic properties for methanol oxidation. J Mater Chem. 2012;22(22):11284-11289.

30. Gurunathan S, Kalishwaralal K, Vaidyanathan R, et al. Biosynthesis, purification and characterization of silver nanoparticles using Escherichia coli. Colloids Surf B Biointerfaces. 2009;74(1):328-335.

31. Gurunathan S, Han JW, Dayem AA, Eppakayala V, Kim JH. Oxidative stress-mediated antibacterial activity of graphene oxide and reduced graphene oxide in Pseudomonas aeruginosa. Int J Nanomedicine. 2012;7: 5901-5914.

32. Gurunathan S, Han J, Park JH, Kim JH. An in vitro evaluation of graphene oxide reduced by Ganoderma spp. in human breast cancer cells (MDA-MB-231). Int J Nanomedicine. 2014;9:1783-1797.

33. Gurunathan S, Han JW, Eppakayala V, Kim JH. Biocompatibility of microbially reduced graphene oxide in primary mouse embryonic fibroblast cells. Colloids Surf B Biointerfaces. 2013;105:58-66.

34. Dreyer DR, Jia HP, Bielawski CW. Graphene oxide: a convenient carbocatalyst for facilitating oxidation and hydration reactions. Angew Chem Int Ed Engl. 2010;49(38):6813-6816.

35. Al-Marri AH, Khan M, Khan M, et al. Pulicaria glutinosa extract: a toolbox to synthesize highly reduced graphene oxide-silver nanocomposites. Int J Mol Sci. 2015;16(1):1131-1142. 
36. Thakur S, Karak N. Green reduction of graphene oxide by aqueous phytoextracts. Carbon N Y. 2012;50(14):5331-5339.

37. Fu CJ, Zhao GG, Zhang HJ, Li S. Evaluation and characterization of reduced graphene oxide nanosheets as anode materials for lithium-ion batteries. Int J Electrochem Sci. 2013;8(5):6269-6280.

38. Gurunathan S, Han J, Kim JH. Humanin: A novel functional molecule for the green synthesis of graphene. Colloids Surf B Biointerfaces. 2013;111:376-383.

39. Nethravathi C, Rajamathi M. Chemically modified graphene sheets produced by the solvothermal reduction of colloidal dispersions of graphite oxide. Carbon N Y. 2008;46(14):1994-1998.

40. Pham TA, Kim JS, Kim JS, Jeong YT. One-step reduction of graphene oxide with L-glutathione. Colloids Surf A Physicochem Eng Asp. 2011; 384(1-3):543-548.

41. Dave SH, Gong CC, Robertson AW, Warner JH, Grossman JC. Chemistry and structure of graphene oxide via direct imaging. ACS Nano. 2016; 10(8):7515-7522.

42. Hu CF, Liu YL, Qin JL, et al. Fabrication of reduced graphene oxide and sliver nanoparticle hybrids for Raman detection of absorbed folic acid a potential cancer diagnostic probe. ACS Appl Mater Interfaces. 2013; 5(11):4760-4768.

43. Shen JF, Shi M, Li N, et al. Facile synthesis and application of Agchemically converted graphene nanocomposite. Nano Res. 2010;3(5) 339-349.

44. Bao Q, Zhang D, Qi P. Synthesis and characterization of silver nanoparticle and graphene oxide nanosheet composites as a bactericidal agent for water disinfection. J Colloid Interface Sci. 2011;360(2):463-470.

45. Das MR, Sarma RK, Saikia R, Kale VS, Shelke MV, Sengupta P. Synthesis of silver nanoparticles in an aqueous suspension of graphene oxide sheets and its antimicrobial activity. Colloids Surf B Biointerfaces. 2011;83(1):16-22.

46. Yang BW, Liu ZM, Guo ZY, et al. In situ green synthesis of silvergraphene oxide nanocomposites by using tryptophan as a reducing and stabilizing agent and their application in SERS. Appl Surf Sci. 2014; 316:22-27.

47. Zhang DH, Liu XH, Wang X. Green synthesis of graphene oxide sheets decorated by silver nanoprisms and their anti-bacterial properties. J Inorg Biochem. 2011;105(9):1181-1186.

48. Akhavan O, Ghaderi E, Aghayee S, Fereydooni Y, Talebi A. The use of a glucose-reduced graphene oxide suspension for photothermal cancer therapy. J Mater Chem. 2012;22(27):13773-13781.

49. de Luna LA, de Moraes AC, Consonni SR, et al. Comparative in vitro toxicity of a graphene oxide-silver nanocomposite and the pristine counterparts toward macrophages. J Nanobiotechnology. 2016;14:12.

50. Martelli L, Ragazzi E, Di Mario F, Basato M, Martelli M. Cisplatin and oxaliplatin cytotoxic effects in sensitive and cisplatin-resistant human cervical tumor cells: time and mode of application dependency. Anticancer Res. 2009;29(10):3931-3937.

51. Moreno D, Zalba S, Navarro I, de Ilarduya CT, Garrido MJ. Pharmacodynamics of cisplatin-loaded PLGA nanoparticles administered to tumor-bearing mice. Eur J Pharm Biopharm. 2010;74(2):265-274.

52. Bhirde AA, Patel S, Sousa AA, et al. Distribution and clearance of PEG-single-walled carbon nanotube cancer drug delivery vehicles in mice. Nanomedicine (Lond). 2010;5(10):1535-1546.

53. Li XH, Chen XJ, Ou WB, et al. Knockdown of creatine kinase B inhibits ovarian cancer progression by decreasing glycolysis. Int J Biochem Cell Biol. 2013;45(5):979-986.

54. Li XX, Wang HL, Wang J, et al. Emodin enhances cisplatin-induced cytotoxicity in human bladder cancer cells through ROS elevation and MRP1 downregulation. BMC Cancer. 2016;16:578.

55. Nel A, Xia T, Madler L, Li N. Toxic potential of materials at the nanolevel. Science. 2006;311(5761):622-627.

56. Porter NA, Caldwell SE, Mills KA. Mechanisms of free radical oxidation of unsaturated lipids. Lipids. 1995;30(4):277-290.

57. Zhou J, Li P, Xue XF, et al. Salinomycin induces apoptosis in cisplatinresistant colorectal cancer cells by accumulation of reactive oxygen species. Toxicol Lett. 2013;222(2):139-145.
58. Maharjan S, Oku M, Tsuda M, Hoseki J, Sakai Y. Mitochondrial impairment triggers cytosolic oxidative stress and cell death following proteasome inhibition. Sci Rep. 2014;4:5896.

59. Wang GQ, Gastman BR, Wieckowski E, et al. Apoptosis-resistant mitochondria in T cells selected for resistance to Fas signaling. $J$ Biol Chem. 2001;276(5):3610-3619.

60. Zamzami N, Marchetti P, Castedo M, et al. Sequential reduction of mitochondrial transmembrane potential and generation of reactive oxygen species in early programmed cell death. $J$ Exp Med. 1995; 182(2):367-377.

61. Zamzami N, Susin SA, Marchetti P, et al. Mitochondrial control of nuclear apoptosis. J Exp Med. 1996;183(4):1533-1544.

62. Melendez-Zajgla J, Cruz E, Maldonado V, Espinoza AM. Mitochondrial changes during the apoptotic process of HeLa cells exposed to cisplatin. Biochem Mol Biol Int. 1999;47(5):765-771.

63. Muldoon LL, Walker-Rosenfeld SL, Hale C, Purcell SE, Bennett LC, Neuwelt EA. Rescue from enhanced alkylator-induced cell death with low molecular weight sulfur-containing chemoprotectants. JPharmacol Exp Ther. 2001;296(3):797-805.

64. Hamers FP, Brakkee JH, Cavalletti E, et al. Reduced glutathione protects against cisplatin-induced neurotoxicity in rats. Cancer Res. 1993; 53(3):544-549.

65. Traverso N, Ricciarelli R, Nitti M, et al. Role of glutathione in cancer progression and chemoresistance. Oxid Med Cell Longev. 2013;2013: 972913.

66. Levine AJ. p53, The cellular gatekeeper for growth and division. Cell. 1997;88(3):323-331.

67. Lowe SW, Ruley HE, Jacks T, Housman DE. p53-Dependent apoptosis modulates the cytotoxicity of anticancer agents. Cell. 1993;74(6): 957-967.

68. Allouche M, Bettaieb A, Vindis C, Rousse A, Grignon C, Laurent G. Influence of Bcl-2 overexpression on the ceramide pathway in daunorubicininduced apoptosis of leukemic cells. Oncogene. 1997;14(15): $1837-1845$.

69. Suen DF, Norris KL, Youle RJ. Mitochondrial dynamics and apoptosis. Genes Dev. 2008;22(12):1577-1590.

70. Hernandez-Flores G, Ortiz-Lazareno PC, Lerma-Diaz JM, et al. Pentoxifylline sensitizes human cervical tumor cells to cisplatin-induced apoptosis by suppressing NF-kappa B and decreased cell senescence. BMC Cancer. 2011;11:483.

71. Porter AG, Janicke RU. Emerging roles of caspase-3 in apoptosis. Cell Death Differ. 1999;6(2):99-104.

72. Eliopoulos AG, Kerr DJ, Herod J, et al. The control of apoptosis and drug resistance in ovarian cancer: influence of $\mathrm{p} 53$ and $\mathrm{Bcl}-2$. Oncogene. 1995;11(7):1217-1228.

73. Lowe SW, Bodis S, McClatchey A, et al. p53 Status and the efficacy of cancer therapy in vivo. Science. 1994;266(5186):807-810.

74. Mroz RM, Schins RPF, Li H, et al. Nanoparticle-driven DNA damage mimics irradiation-related carcinogenesis pathways. Eur Respir J. 2008; 31(2):241-251.

75. Pariente R, Pariente JA, Rodriguez AB, Espino J. Melatonin sensitizes human cervical cancer HeLa cells to cisplatin-induced cytotoxicity and apoptosis: effects on oxidative stress and DNA fragmentation. J Pineal Res. 2016;60(1):55-64.

76. Wong VK, Li T, Law BY, et al. Saikosaponin-D, a novel SERCA inhibitor, induces autophagic cell death in apoptosis-defective cells. Cell Death Dis. 2013;4:e720.

77. Hu LL, Sun SL, Wang TP, et al. Oncolytic Newcastle disease virus triggers cell death of lung cancer spheroids and is enhanced by pharmacological inhibition of autophagy. Am J Cancer Res. 2015;5(12): 3612-3623.

78. Hanahan D, Weinberg RA. Hallmarks of cancer: the next generation. Cell. 2011;144(5):646-674.

79. Bao LJ, Jaramillo MC, Zhang ZB, et al. Nrf2 induces cisplatin resistance through activation of autophagy in ovarian carcinoma. Int J Clin Exp Pathol. 2014;7(4):1502-1513. 
80. Maskey D, Yousefi S, Schmid I, et al. ATG5 is induced by DNAdamaging agents and promotes mitotic catastrophe independent of autophagy. Nat Commun. 2013;4:2130.

81. Mehrpour M, Esclatine A, Beau I, Codogno P. Autophagy in health and disease. 1. Regulation and significance of autophagy: an overview. Am J Physiol Cell Physiol. 2010;298(4):C776-C785.

82. Lin WM, Li ZG. Blockage of cisplatin-induced autophagy sensitizes cervical cancer cells to cisplatin. Genet Mol Res. 2015;14(4): 16905-16912.

83. Huang YP, Guerrero-Preston R, Ratovitski EA. Phospho- $\Delta$ Np63 $\alpha-$ dependent regulation of autophagic signaling through transcription and micro-RNA modulation. Cell Cycle. 2012;11(6):1247-1259.

84. Han JW, Gurunathan S, Jeong JK, et al. Oxidative stress mediated cytotoxicity of biologically synthesized silver nanoparticles in human lung epithelial adenocarcinoma cell line. Nanoscale Res Lett. 2014;9:459.

85. Degenhardt K, Mathew R, Beaudoin B, et al. Autophagy promotes tumor cell survival and restricts necrosis, inflammation, and tumorigenesis. Cancer Cell. 2006;10(1):51-64.

86. Gozuacik D, Kimchi A. Autophagy as a cell death and tumor suppressor mechanism. Oncogene. 2004;23(16):2891-2906.

87. Liang XH, Jackson S, Seaman M, et al. Induction of autophagy and inhibition of tumorigenesis by beclin 1. Nature. 1999;402(6762):672-676.

88. Mathew R, White E. Why sick cells produce tumors: the protective role of autophagy. Autophagy. 2007;3(5):502-505.
89. Chen YQ, McMillan-Ward E, Kong JM, Israels SJ, Gibson SB. Mitochondrial electron-transport-chain inhibitors of complexes I and II induce autophagic cell death mediated by reactive oxygen species. J Cell Sci. 2007;120(23):4155-4166.

90. Duan WJ, Jin XY, Li QS, Tashiro S, Onodera S, Ikejima T. Silibinin induced autophagic and apoptotic cell death in HT1080 cells through a reactive oxygen species pathway. J Pharmacol Sci. 2010;113(1): 48-56.

91. Hu F, Wei F, Wang YL, Wu BB, Fang Y, Xiong B. EGCG synergizes the therapeutic effect of cisplatin and oxaliplatin through autophagic pathway in human colorectal cancer cells. J Pharmacol Sci. 2015; 128(1):27-34.

92. Fruehauf JP, Meyskens FL. Reactive oxygen species: a breath of life or death? Clin Cancer Res. 2007;13(3):789-794.

93. Liao L, Liu J, Dreaden EC, et al. Convergent synthetic platform for single-nanoparticle combination cancer therapy: ratiometric loading and controlled release of cisplatin, doxorubicin, and camptothecin. $\mathrm{J} \mathrm{Am}$ Chem Soc. 2014;136(16):5896-5899.

94. Pathak RK, Dhar S. A nanoparticle cocktail: temporal release of predefined drug combinations. J Am Chem Soc. 2015;137(26): 8324-8327.

95. Pathak RK, Dhar S. Combined chemo-anti-inflammatory prodrugs and nanoparticles. Synlett. 2016;27(11):1607-1612.
International Journal of Nanomedicine

\section{Publish your work in this journal}

The International Journal of Nanomedicine is an international, peerreviewed journal focusing on the application of nanotechnology in diagnostics, therapeutics, and drug delivery systems throughout the biomedical field. This journal is indexed on PubMed Central, MedLine, CAS, SciSearch ${ }^{\circledR}$, Current Contents ${ }^{\circledR} /$ Clinical Medicine,

\section{Dovepress}

Journal Citation Reports/Science Edition, EMBase, Scopus and the Elsevier Bibliographic databases. The manuscript management system is completely online and includes a very quick and fair peer-review system, which is all easy to use. Visit http://www.dovepress.com/ testimonials.php to read real quotes from published authors. 